\title{
Temporal integration of loudness in listeners with hearing losses of primarily cochlear
} origin

Buus, Søren; Florentine, Mary; Poulsen, Torben

Published in:

Acoustical Society of America. Journal

Link to article, DOI:

$10.1121 / 1.424673$

Publication date:

1999

Document Version

Publisher's PDF, also known as Version of record

Link back to DTU Orbit

Citation (APA):

Buus, S., Florentine, M., \& Poulsen, T. (1999). Temporal integration of loudness in listeners with hearing losses of primarily cochlear origin. Acoustical Society of America. Journal, 105(6), 3464-3480.

https://doi.org/10.1121/1.424673

\section{General rights}

Copyright and moral rights for the publications made accessible in the public portal are retained by the authors and/or other copyright owners and it is a condition of accessing publications that users recognise and abide by the legal requirements associated with these rights.

- Users may download and print one copy of any publication from the public portal for the purpose of private study or research.

- You may not further distribute the material or use it for any profit-making activity or commercial gain

- You may freely distribute the URL identifying the publication in the public portal

If you believe that this document breaches copyright please contact us providing details, and we will remove access to the work immediately and investigate your claim 


\title{
Temporal integration of loudness in listeners with hearing losses of primarily cochlear origin ${ }^{\text {a) }}$
}

\author{
Søren Buus ${ }^{\text {b) }}$ \\ Communication and Digital Signal Processing Center, Department of Electrical and Computer Engineering \\ (409DA), Northeastern University, Boston, Massachusetts 02115 \\ Mary Florentine \\ Department of Speech-Language Pathology and Audiology (133FR) and Institute for Hearing, Speech, and \\ Language, Northeastern University, Boston, Massachusetts 02115 \\ Torben Poulsen \\ Department of Acoustic Technology (Building 352), Technical University of Denmark, DK-2800 Lyngby, \\ Denmark
}

(Received 5 November 1998; revised 22 January 1999; accepted 11 March 1999)

\begin{abstract}
To investigate how hearing loss of primarily cochlear origin affects the loudness of brief tones, loudness matches between 5- and 200-ms tones were obtained as a function of level for 15 listeners with cochlear impairments and for seven age-matched controls. Three frequencies, usually $0.5,1$, and $4 \mathrm{kHz}$, were tested in each listener using a two-interval, two-alternative forced-choice (2I, 2AFC) paradigm with a roving-level, up-down adaptive procedure. Results for the normal listeners generally were consistent with published data [e.g., Florentine et al., J. Acoust Soc. Am. 99, 1633-1644 (1996)]. The amount of temporal integration-defined as the level difference between equally loud short and long tones-varied nonmonotonically with level and was largest at moderate levels. No consistent effect of frequency was apparent. The impaired listeners varied widely, but most showed a clear effect of level on the amount of temporal integration. Overall, their results appear consistent with expectations based on knowledge of the general properties of their loudness-growth functions and the equal-loudness-ratio hypothesis, which states that the loudness ratio between equal-SPL long and brief tones is the same at all SPLs. The impaired listeners' amounts of temporal integration at high SPLs often were larger than normal, although it was reduced near threshold. When evaluated at equal SLs, the amount of temporal integration well above threshold usually was in the low end of the normal range. Two listeners with abrupt high-frequency hearing losses (slopes $>50 \mathrm{~dB} /$ octave) showed larger-than-normal maximal amounts of temporal integration (40 to $50 \mathrm{~dB}$ ). This finding is consistent with the shallow loudness functions predicted by our excitation-pattern model for impaired listeners [Florentine et al., in Modeling Sensorineural Hearing Loss, edited by W. Jesteadt (Erlbaum, Mahwah, NJ, 1997), pp. 187-198]. Loudness functions derived from impaired listeners' temporal-integration functions indicate that restoration of loudness in listeners with cochlear hearing loss usually will require the same gain whether the sound is short or long. (C) 1999 Acoustical Society of America. [S0001-4966(99)04206-X]
\end{abstract}

PACS numbers: 43.66.Sr, 43.66.Cb, 43.66.Mk, 43.66.Ba [JWH]

\section{INTRODUCTION}

The purpose of the present study is to investigate temporal integration of loudness in listeners with hearing impairments of primarily cochlear origin. Whereas considerable knowledge exists about the loudness of long-duration sounds in impaired listeners (for review, see Hellman and Meiselman, 1993; Moore, 1995; Moore and Glasberg, 1997), little is known about the loudness of brief sounds. Because most natural sounds are not steady state, but have amplitude peaks

\footnotetext{
${ }^{a)}$ Parts of this paper were presented at the Hearing Aid Research and Development Conference, September 1997, NIDCD/VA Bethesda, MD [Buus et al., Proceedings of the 2nd Biennial Hearing Aid Research and Development Conference (NIDCD/VA, Bethesda, MD, Sept. 1997), 42] and at the ASHA meeting, November 1997, Boston, MA [Buus et al., ASHA Leader 2(15), 143].

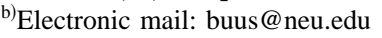

that typically are much shorter than the $50-150$-ms integration time generally assumed for loudness (for review, see Scharf, 1978), knowledge of the loudness functions for brief sounds may be important for hearing-aid fitting and for general understanding of impaired listeners' auditory perception. Moreover, our recent studies (Florentine et al., 1996; Buus et al., 1997; Florentine et al., 1998) indicate that temporal integration of loudness may provide rather direct information about the form of the loudness functions for both brief and long sounds.

To our knowledge, Pedersen and Poulsen's (1973) study on temporal integration of loudness in impaired hearing is the only one published. They tested 24 listeners with cochlear impairments due to presbyacusis. The results indicated that the impaired listeners' amount of temporal integration-defined as the level difference between equally 
loud short and long tones-was normal at $75 \mathrm{~dB}$ SPL and larger than normal at $95 \mathrm{~dB}$ SPL. The normal and largerthan-normal temporal integration for loudness found by Pedersen and Poulsen (1973) contrasts with the reduced temporal integration that is generally found in measurements of detection thresholds for brief signals in impaired listeners (e.g., Florentine et al., 1988; Carlyon et al., 1990; for review, see Moore, 1995) and certainly warrants further study.

To expand on Pedersen and Poulsen's (1973) study, the present study aims to investigate how the amount of temporal integration for loudness varies with level in impaired listeners. The effect of level is important because the amount of temporal integration varies markedly with level in normal listeners (e.g., Stephens, 1973; Poulsen, 1981; Florentine et al., 1996, 1998; Buus et al., 1997) and the outcome of comparisons between normal and impaired hearing appears to depend on the SPL (Pedersen and Poulsen, 1973). The outcome may also depend on whether normal and impaired listeners are compared at equal SL or equal SPL, as indicated by the contrast between temporal integration for detection (an equal-SL comparison) and for loudness (compared at equal SPLs). To provide insight into the effects of audiometric configurations, measurements were obtained using listeners with cochlear impairments in a variety of audiometric configurations. To allow comparisons at equal SLs and equal SPLs, temporal integration for detection and temporal integration of loudness was measured as a function of level.

\section{METHOD}

\section{A. Stimuli}

The stimuli were tone bursts with equivalent rectangular durations of 5 and $200 \mathrm{~ms}$. The 5 -ms tones consisted of a $6.67-\mathrm{ms}$ raised-cosine rise followed immediately by a $6.67-\mathrm{ms}$ raised-cosine fall. The $200-\mathrm{ms}$ tones had a $195-\mathrm{ms}$ steady-state segment between the $6.67-\mathrm{ms}$ rise and fall. These envelope shapes ensured that most of the tone bursts' energy was contained within the critical bandwidth for all test frequencies. Even for the 5-ms tone burst, the energy within the 100-Hz-wide critical band centered at $500 \mathrm{~Hz}$ (Zwicker, 1961; Scharf, 1970) was only $1.3 \mathrm{~dB}$ less than the overall energy. [The auditory-filter bandwidth at $500 \mathrm{~Hz}$ is only about $75 \mathrm{~Hz}$, but loudness of a constant-SPL stimulus remains constant until its bandwidth exceeds the larger critical bandwidth (see Moore and Glasberg, 1986). The present stimuli were chosen with the aim of keeping loudness the same as that for a narrow-band sound. Thus, the critical bandwidth was used for evaluation of the 5-ms tones' spectral splatter.]

The fixed-level stimuli ranged from $5 \mathrm{~dB}$ SL to about $120 \mathrm{~dB}$ SPL for the 5-ms tone or the highest level that the listener could comfortably tolerate, whichever was lower. Levels were chosen in 5-dB steps up to $30 \mathrm{~dB}$ SL and in $10-\mathrm{dB}$ steps at higher SLs. The test frequencies usually were $0.5,1$, and $4 \mathrm{kHz}$, but one normal listener was also tested at $8 \mathrm{kHz}$ and one impaired listener was tested at $8 \mathrm{kHz}$ instead of $0.5 \mathrm{kHz}$ to obtain measurements at two frequencies with hearing loss.

\section{B. Procedure}

\section{Absolute thresholds}

To obtain a reference for setting the sensation levels, absolute thresholds were measured for each of the stimuli used in the loudness-balance experiment. The thresholds were obtained with an adaptive procedure in a two-interval, two-alternative forced-choice (2I, 2AFC) paradigm. Each trial contained two observation intervals, which were marked by lights and separated by $500 \mathrm{~ms}$. The signal was presented in either the first or the second observation interval with equal a priori probability. The listener's task was to indicate which interval contained the signal by pressing a key on a small computer terminal. Two hundred milliseconds after the listener responded, the correct answer was indicated by a 200-ms light. Following the feedback, the next trial began after a 500-ms delay.

A single threshold measurement was based on three interleaved adaptive tracks. For each track, the level of the signal initially was set approximately $15 \mathrm{~dB}$ above the listener's expected threshold. It decreased following three consecutive correct responses and increased following one incorrect response. The step size was $5 \mathrm{~dB}$ until the second reversal, after which it was reduced to $2 \mathrm{~dB}$. Reversals occurred when successive signal levels changed direction from increasing to decreasing, or vice versa. On each trial, the track was selected at random among the tracks that had not yet ended, which they did after five reversals. The threshold for one track was calculated as the average of the signal levels at the fourth and fifth reversals. One threshold measurement was taken as the average threshold across the three tracks. This procedure converged on the signal level yielding 79.4\% correct responses (Levitt, 1971). Three such threshold measurements (for a total of nine tracks) were obtained for each listener and stimulus. The average across all measurements was used as the reference to set the sensation level in the loudness-balance experiments.

\section{Loudness matches}

Loudness matches between 5- and 200-ms tones were obtained with a roving-level adaptive procedure in a $2 \mathrm{I}$, 2AFC paradigm, similar to that used in a recent study (Buus et al., 1998). On each trial, the listener heard two tones separated by $500 \mathrm{~ms}$. The fixed-level tone followed the variable tone or the reverse with equal a priori probability. The listener's task was to indicate which sound was louder by pressing a key on a small computer terminal. The response initiated the next trial after a 700-ms delay. No feedback was given.

To reduce biases that may occur when only a single fixed sound is presented in a series of trials (e.g., Florentine et al., 1996), six to 12 interleaved adaptive tracks were used to obtain concurrent loudness matches at three to six levels with both the short and the long tone varied. The track for each trial was selected at random from all tracks that had not yet ended, which they did after nine reversals. This procedure produced a random variation in overall loudness, which forced the listeners to base their responses only on loudness judgments of the two sounds presented in the trial. [For fur- 
ther discussion of roving-level loudness-matching procedures, see Buus et al. (1997).]

Because no more than six levels could be tested concurrently, the complete range of fixed levels usually was divided into two or three ranges as necessary to encompass each listener's dynamic range. For normal listeners, a low range included fixed levels between 5 and $20 \mathrm{~dB}$ SL, a middle range included levels between 25 and $50 \mathrm{~dB}$ SL, and a high range included levels between 60 and $90 \mathrm{~dB}$ SL. For impaired listeners, the ranges varied among listeners and frequencies to ensure that each block of trials encompassed reasonable ranges of fixed levels for both short and long tones. If two or fewer levels within a range used for normal listeners could be tested for a given impaired listener and frequency, the number of ranges was reduced and the complete range of levels was redistributed to yield blocks with approximately equal numbers of tracks. If fewer than seven levels could be tested for a given listener and frequency, all levels were usually tested in a single block.

Each track began with the variable stimulus set approximately $15 \mathrm{~dB}$ below the expected equal-loudness level. (If that level was below threshold, the variable stimulus was set to threshold.) This choice of starting levels ensured that the listener heard some trials in which the short tone was clearly louder and some in which the long tone was clearly louder. For each track, the level of the variable tone was adjusted according to a simple up-down procedure. If the listener indicated that the variable tone was louder than the fixed tone, its level was reduced; otherwise, it was increased. The step size was $5 \mathrm{~dB}$ until the fourth reversal, after which it was reduced to $2 \mathrm{~dB}$. This procedure made the variable tone converge towards the level at which it was judged louder than the fixed tone in $50 \%$ of the trials (Levitt, 1971). The average level of the last four reversals was used as an estimate of the level at which the variable tone had the same loudness as the fixed-level tone (cf. Jesteadt, 1980). Three such matches were obtained for each listener and condition.

\section{Apparatus}

An APR 486/33 PC-compatible computer with a signal processor (TDT AP2) generated the stimuli, sampled the listeners' responses, and executed the adaptive procedures. The tone bursts were generated digitally with a $50-\mathrm{kHz}$ sample rate and reproduced by a 16-bit digital-to-analog (D/A) converter (TDT DD1). The output from the D/A was attenuated (TDT PA4), low-pass filtered (TDT FT5, $f_{c}=20 \mathrm{kHz}, 190$ $\mathrm{dB} /$ octave), attenuated again (TDT PA4), and led to a headphone amplifier (TDT HB6), which fed one earpiece of a Sony MDR-V6 headset. This setup ensured that the stimulus level could be controlled with a dynamic range of at least $130 \mathrm{~dB}$. The listeners were seated in a sound-attenuating booth.

For routine calibration, the output of the headphone amplifier was led to a 16-bit analog-to-digital (A/D) converter (TDT DD1), such that the computer could sample the waveform, calculate its spectrum and rms voltage, and display the results before each set of matches. [The SPLs reported below presume a frequency-independent output of $116 \mathrm{~dB}$ SPL for an input of $1 \mathrm{~V} \mathrm{rms}$. The Sony MDR-V6 headset has a rea- sonably flat $( \pm 5 \mathrm{~dB})$ free-field response across the range of test frequencies. The SPL of $116 \mathrm{~dB}$ is close to that measured at $1 \mathrm{kHz}$ in a 6-cc coupler (B\&K 4152).]

\section{Listeners}

Sixteen ears of 15 listeners with hearing impairments of primarily cochlear origin were tested. The origin of the hearing loss was diagnosed by the listeners' ENT physicians on the basis of a standardized audiological test battery, medical tests, and the listeners' history. Table I shows the diagnostic information for the listeners. According to excitation-pattern models of loudness in impaired listeners (Florentine and Zwicker, 1979; Florentine et al., 1997; Moore and Glasberg, 1997), the form of the loudness function may depend on the impaired listener's audiometric configuration. Certainly, it has been shown that level discrimination in impaired listeners depends on the audiometric configuration in a way that is consistent with predictions of excitation-pattern models (Florentine et al., 1993). Therefore, the impaired listeners were divided into five groups based on the overall configurations of their hearing losses as indicated by the listener IDs shown in the first column. (A sixth group of normal controls is shown at the bottom.) If the hearing loss increased more than $50 \mathrm{~dB}$ over any octave, it was characterized as an abrupt loss (listeners A1 and A2); such a steep loss is likely to indicate that inner-hair cells are missing or nonfunctional in some frequency region starting at the beginning of the slope (Hellman and Meiselman, 1993; Florentine et al., 1997). If the hearing loss was not abrupt and decreased $15 \mathrm{~dB}$ or more over any two-octave interval, it was characterized as a rising loss (R1 to R3). If the loss was neither abrupt nor rising, it was characterized as flattish if it increased $20 \mathrm{~dB}$ or less over all two-octave intervals (F1 to F3), and as falling otherwise. Because eight ears of seven listeners fell into the falling-loss category, they were further subdivided into mild-to-moderate losses (MF1 to MF4) and moderately-severe-to-severe losses (SF1 to SF3).

The second column shows the listeners' genders and the third, their ages. The impaired listeners' ages ranged from 32 to 72 years, with an average of 46 years and a standard deviation of 12.5 years. The test ear is indicated in the fourth column and the listeners' etiologies are shown in the fifth column. Columns six through 15 show the audiometric thresholds in $\mathrm{dB}$ HL at the standard audiometric frequencies. The test frequencies used for each listener are indicated by the bold entries, which show that the measurements encompassed conditions with hearing losses ranging from no significant loss to $90 \mathrm{~dB}$ HL.

Seven listeners with normal hearing served as agematched controls. Their ages ranged from 25 to 58 years. The average age was 46 years and the standard deviation 11.7 years. They had no history of hearing difficulties and their audiometric thresholds were $15 \mathrm{~dB}$ HL or less at and below $4 \mathrm{kHz}$; most of the middle-aged listeners had a small threshold elevation at $6 \mathrm{kHz}$ and $\mathrm{N} 7$ had a threshold of $25 \mathrm{~dB}$ $\mathrm{HL}$ at $8 \mathrm{kHz}$. Listener $\mathrm{N} 1$ is the first author and N2 is the third author. They and listener N3 were highly trained listeners; the remaining normal listeners had no prior experience in psychoacoustic experiments. Due to timing constraints, 
TABLE I. Diagnostic information for the listeners. (See the text for further information.)

\begin{tabular}{|c|c|c|c|c|c|c|c|c|c|c|c|c|c|c|}
\hline ID & Gender & Age & Ear & Etiology & 125 & 250 & 500 & $1 \mathrm{k}$ & $1.5 \mathrm{k}$ & $2 \mathrm{k}$ & $3 \mathrm{k}$ & $4 \mathrm{k}$ & $6 \mathrm{k}$ & $8 \mathrm{kHz}$ \\
\hline A1 & $\mathrm{F}$ & 51 & $\mathrm{~L}$ & $\begin{array}{l}\text { Hereditary, } \\
\text { noncongenital }\end{array}$ & -10 & -10 & -5 & 60 & 60 & 55 & 45 & 45 & & 65 \\
\hline A2 & $\mathrm{F}$ & 61 & $\mathrm{~L}$ & Hereditary & 5 & 10 & 5 & 5 & 35 & 60 & 85 & 90 & 90 & 95 \\
\hline $\mathrm{R} 1$ & $\mathrm{~F}$ & 50 & $\mathrm{R}$ & $\begin{array}{l}\text { Hereditary, } \\
\text { noncongenital }\end{array}$ & -5 & 5 & 20 & 45 & 50 & 45 & 35 & 30 & & 60 \\
\hline $\mathrm{R} 2$ & M & 37 & $\mathrm{~L}$ & $\begin{array}{l}\text { Hereditary } \\
\text { Konigsmark }\end{array}$ & 55 & 50 & 50 & 40 & & 35 & & 30 & 55 & 55 \\
\hline R3 & M & 53 & $\mathrm{~L}$ & Unknown & 60 & 75 & 70 & 65 & 65 & 55 & 50 & 45 & & 35 \\
\hline $\mathrm{F} 1$ & $\mathrm{M}$ & 36 & $\mathrm{~L}$ & Hereditary & & 35 & 40 & 45 & & 55 & & 55 & & 45 \\
\hline $\mathrm{F} 2$ & $\mathrm{~F}$ & 33 & $\mathrm{~L}$ & Hereditary & 45 & 50 & 50 & 65 & & 65 & & 70 & & 70 \\
\hline F3 & $\mathrm{F}$ & 35 & $\mathrm{~L}$ & $\begin{array}{l}\text { Congenital, } \\
\text { jaundice }\end{array}$ & & 70 & 70 & 80 & & 80 & & 90 & & 85 \\
\hline MF1 & M & 45 & $\mathrm{R}$ & Unknown & 5 & 10 & 15 & 5 & & 0 & 20 & 35 & 50 & 55 \\
\hline MF2 & M & 65 & $\mathrm{~L}$ & $\begin{array}{l}\text { Hereditary, } \\
\text { noncongenital }\end{array}$ & 0 & 0 & 15 & 30 & 40 & 40 & 50 & 65 & & 75 \\
\hline MF3 & $\mathrm{F}$ & 49 & $\mathrm{~L}$ & $\begin{array}{l}\text { Hereditary, } \\
\text { noncongenital }\end{array}$ & 0 & 10 & 20 & 35 & 45 & 45 & 45 & 50 & & 80 \\
\hline MF4 & $\mathrm{F}$ & 40 & $\mathrm{R}$ & $\begin{array}{l}\text { Hereditary, } \\
\text { congenital }\end{array}$ & 15 & 20 & 45 & 50 & & 45 & & 50 & & 45 \\
\hline \multirow[t]{2}{*}{ SF1 } & \multirow[t]{2}{*}{ M } & \multirow[t]{2}{*}{72} & $\mathrm{~L}$ & Unknown, & 20 & 25 & 40 & $\mathbf{5 0}$ & 55 & 55 & 60 & 60 & 75 & 80 \\
\hline & & & $\mathrm{R}$ & noncongenital & 20 & 25 & 40 & 60 & 65 & 70 & 75 & 80 & 95 & $>100$ \\
\hline $\mathrm{SF} 2$ & M & 32 & $\mathrm{R}$ & $\begin{array}{l}\text { Hereditary, } \\
\text { noncongenital }\end{array}$ & 10 & 20 & 35 & 70 & 75 & 65 & 65 & 75 & & 85 \\
\hline SF3 & $\mathrm{F}$ & 35 & $\mathrm{R}$ & $\begin{array}{l}\text { Sudden, } \\
\text { unknown }\end{array}$ & 10 & 40 & 60 & 80 & & 75 & & 70 & & 70 \\
\hline N1 & M & 45 & $\mathrm{~L}$ & Normal & 5 & -5 & 0 & 0 & & 5 & 0 & 0 & 20 & 10 \\
\hline $\mathrm{N} 2$ & M & 53 & $\mathrm{R}$ & Normal & 5 & 0 & $\mathbf{0}$ & $\mathbf{0}$ & & 0 & 0 & $\mathbf{0}$ & 30 & 15 \\
\hline N3 & M & 25 & $\mathrm{~L}$ & Normal & 5 & 0 & 5 & $\mathbf{0}$ & & 0 & & -5 & & 5 \\
\hline $\mathrm{N} 4$ & $\mathrm{M}$ & 35 & $\mathrm{R}$ & Normal & 5 & 0 & 0 & 5 & & 5 & 15 & 15 & 15 & 5 \\
\hline N5 & $\mathrm{F}$ & 50 & $\mathrm{R}$ & Normal & 5 & 5 & 5 & 5 & & 0 & 0 & 10 & 0 & 10 \\
\hline N6 & $\mathrm{F}$ & 53 & $\mathrm{~L}$ & Normal & 15 & 5 & 0 & 0 & & 0 & 10 & 15 & 20 & 15 \\
\hline N7 & M & 58 & $\mathrm{R}$ & Normal & 5 & 0 & 0 & 5 & & 10 & & 10 & 20 & 25 \\
\hline
\end{tabular}

naive normal and impaired listeners practiced at most for 15 minutes, but careful instructions usually rendered practice unnecessary.

\section{E. Data analysis}

For each listener, frequency, and SL, two separate points of subjective equality were calculated for each stimulus pair: the average of the tracks with the short tone fixed and the average of the tracks with the long tone fixed. For each listener and frequency, polynomial fits were then made to the combined data obtained with the long and the short tone varied. Such fits were used because they provided a good description of the entire data set, while avoiding problems of how to average measurements taken at different loudness levels. Visual inspection was used to determine a range of polynomial orders that provided a good fit to the data. The lowest-order polynomial within the range was used unless a higher-order polynomial appeared to follow the data markedly better over some range. The order of the polynomials ranged from two to eight, but third- or fourth-order polynomials were used in most cases. Generally, the fits were quite good as indicated by an average $r^{2}$ of 0.968 . The resulting polynomials were then used to summarize the amount of temporal integration as a function of level for each listener and frequency by calculating the level difference between the
5- and 200-ms tones as a function of level of the 200-ms tone.

To examine the statistical significance of the effects of stimulus variables and differences among normal listeners, a four-way analysis of variance (ANOVA) (SL of fixed stimulus $\times$ frequency $\times$ long or short variable $\times$ listener) for repeated measures was performed (DATA DESK 6.0.2, Data Description, Inc., Ithaca, NY, 1997). The dependent variable for this analysis was the level difference $\left(L_{5 \mathrm{~ms}}-L_{200 \mathrm{~ms}}\right)$ between two equally loud 5- and 200-ms tones. Scheffé post hoc tests for contrast (DATA DESK 6.0.2, 1997) were performed when appropriate to explore sources of significant effects and interactions. For all statistical tests, differences were considered significant when $p \leqslant 0.05$.

To examine the effects of stimulus variables and differences among the different audiometric configurations, a fourway ANOVA [SL of fixed stimulus $\times$ frequency $\times$ long or short variable $\times$ group (five levels: abrupt, rising, flat, falling, or normal)] was performed (DATA DESK 6.0.2, 1997) with the level difference $\left(L_{5 \mathrm{~ms}}-L_{200 \mathrm{~ms}}\right)$ as the dependent variable. To limit the number of missing data, the analysis included only levels between 5 and $40 \mathrm{~dB}$ SL and only frequencies of $0.5,1$, and $4 \mathrm{kHz}$. Again, Scheffé post hoc tests for contrast (DATA DESK 6.0.2, 1997) were used to explore sources of significant effects and interactions. 


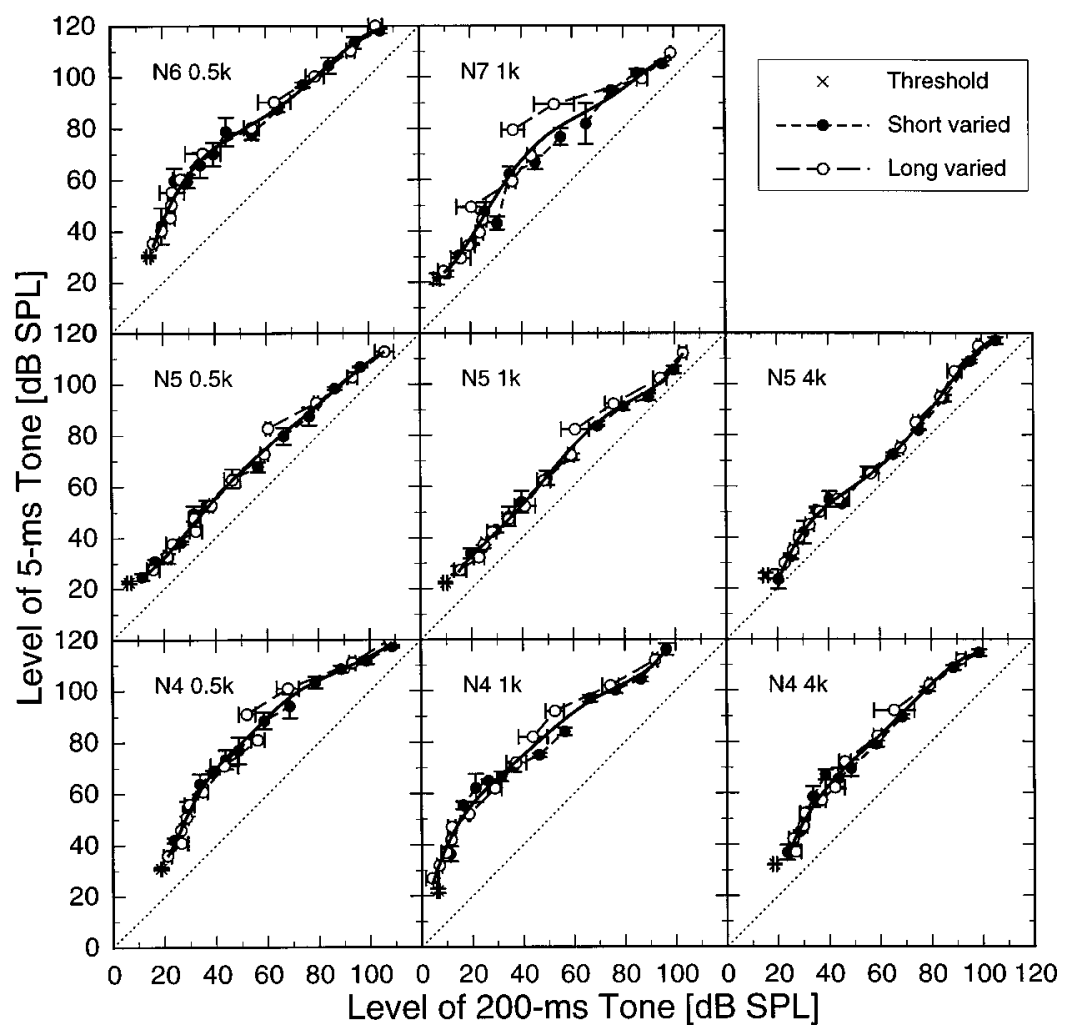

FIG. 1. Loudness-balance judgments by four untrained normal listeners. The level of the 5 -ms tone is plotted as a function of the level of the 200-ms tone. The unfilled symbols show data obtained when the 200-ms tones were varied; the filled symbols show data obtained when the 5-ms tones were varied. Each column shows the data for a different frequency. The top row shows the data for listeners N6 and N7, who were tested at only one frequency. The two lower rows of panels show the data for listeners N4 and N5, who were tested at all three frequencies. The error bars show plus and minus one standard error calculated across the three repetitions for each condition. The solid lines show polynomial fits to the data and the dotted lines indicate equal SPLs for the 5- and 200-ms tones. The distance between the dotted and solid lines indicates the amount of temporal integration.

\section{RESULTS}

\section{A. Normal listeners}

Figure 1 shows the data obtained for the untrained normal listeners. The listeners' judgments were generally quite consistent, as indicated by the small error bars. The average standard error was $2.3 \mathrm{~dB}$. (It was even smaller for the trained normal listeners, $1.8 \mathrm{~dB}$; across all the normal listeners it was $2.0 \mathrm{~dB}$.) The roving-level procedure appeared successful in reducing biases. The data obtained with the 5-ms tone varied and with the 200-ms tone varied generally lie on a single smooth function, but a few notable exceptions are apparent (e.g., listener $\mathrm{N} 4$ at 0.5 and $1 \mathrm{kHz}$ and $\mathrm{N} 7$ at $1 \mathrm{kHz}$ ). For these data sets, the judgments obtained with the 5-ms tone fixed at 60 and $70 \mathrm{~dB}$ SL (i.e., when the long tone was varied and the loudness level was in the low end of the high range) deviate considerably from the smooth function and show much larger amounts of temporal integration than the other data. This phenomenon also was apparent in several data sets for the trained normal listeners and in some data sets for impaired listeners tested at frequencies with nearnormal thresholds. Despite these occasional deviations, a polynomial fitted to the combined data for a single listener and frequency generally summarized the data quite accurately, as indicated by the solid lines. Across all the normal listeners (a total of 18 functions), $r^{2}$ ranges from 0.957 to 0.997 with an average of 0.982 . In the following, these poly-

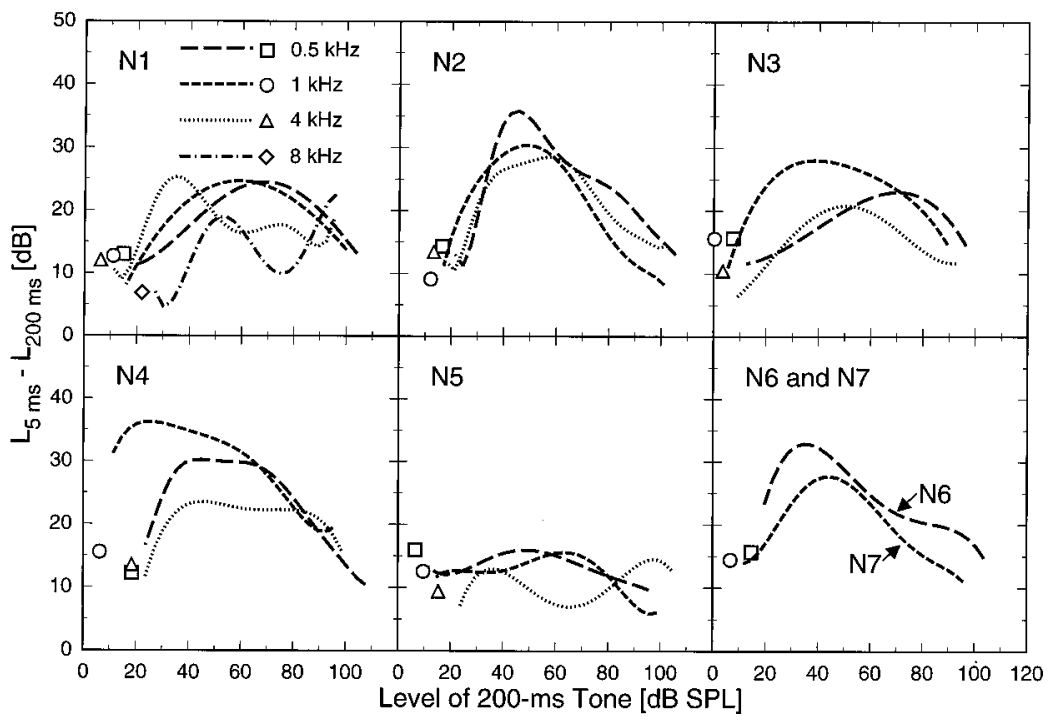

FIG. 2. The amount of temporal integration, defined as the level difference between equally loud 5- and 200-ms tones, for normal listeners is plotted as a function of the SPL of the 200-ms tones. Each panel shows data for a different listener, except that the lower-right panel combines the data for N6, who was tested only at $0.5 \mathrm{kHz}$, and $\mathrm{N} 7$, who was tested only at $1 \mathrm{kHz}$. The symbols show the data for detection thresholds and the lines show the data for loudness matches, which are derived from the fitted polynomials (see Fig. 1). As indicated by the legend in the top-left panel, different symbols and line types indicate frequency. 
nomials are used to characterize how the amount of temporal integration varies with level for each listener and frequency.

Figure 2 shows the amount of temporal integration as a function of level for all the normal listeners. The lines show the level difference between equally loud 5- and 200-ms tones plotted as a function of the level of the 200-ms tones. The threshold data are shown by the symbols. Each panel shows data for a different listener, except that the data for N6 and N7 are combined in the lower-right panel. The amounts of temporal integration for detection range from 7 to $16 \mathrm{~dB}$ with no obvious differences among listeners and frequencies, except that the 7-dB value is obtained at $8 \mathrm{kHz}$ (the secondlowest value is $9 \mathrm{~dB}$ at $1 \mathrm{kHz}$ for $\mathrm{N} 2$ ). The average amounts of temporal integration for detection are $14.5 \mathrm{~dB}$ at $0.5 \mathrm{kHz}$, $13.3 \mathrm{~dB}$ at $1 \mathrm{kHz}$, and $11.8 \mathrm{~dB}$ at $4 \mathrm{kHz}$.

The amounts of temporal integration for loudness vary considerably more across listeners, but, again, there is no obvious trend across frequency. The temporal-integration functions are quite similar across frequency for some listeners (e.g., N2 and N5) and when clear differences are apparent, they are not consistent across listeners (e.g., N1 and N4). For all listeners (except perhaps N5) and all frequencies, the amount of temporal integration clearly varies nonmonotonically with level and is largest at moderate levels. With a few exceptions, the amount of temporal integration for loudness at low levels approaches that obtained for detection. As the level increases, the amount of temporal integration increases, often dramatically. The maximal amounts of temporal integration vary from $13 \mathrm{~dB}(\mathrm{~N} 5$ at $4 \mathrm{kHz} ; 14.5 \mathrm{~dB}$ if the second maximum at $97 \mathrm{~dB}$ SPL is used) to $36 \mathrm{~dB}(\mathrm{~N} 2$ at $0.5 \mathrm{kHz}$ and $\mathrm{N} 4$ at $1 \mathrm{kHz})$. The averages of the maxima are $27 \mathrm{~dB}( \pm 7.3$ $\mathrm{dB}$ standard deviation) at $0.5 \mathrm{kHz}, 27 \mathrm{~dB}$ at $1 \mathrm{kHz}( \pm 7.7$ $\mathrm{dB})$, and $22 \mathrm{~dB}( \pm 5.9 \mathrm{~dB})$ at $4 \mathrm{kHz}$. No obvious relations are apparent among the maximal amount of temporal integration for loudness, the level (SPL or SL) at which the maximum occurs, the amount of temporal integration for detection, and the detection threshold. At high levels, the amounts of temporal integration generally decrease to reach roughly the same values as those obtained for detection.

To provide a comparison for the data from the impaired listeners, the combined data for the normal listeners are shown as functions of SPL in Fig. 3 and SL in Fig. 4. Because no consistent effect of frequency was apparent across listeners, the data are shown together for frequencies of 0.5 (long-dashed lines), 1 (short-dashed lines), and $4 \mathrm{kHz}$ (dotted lines). The two graphs are quite similar because the normal listeners' thresholds encompass only a relatively narrow range of SPLs. Both show that the amounts of temporal integration encompass quite large ranges, especially at moderate levels where the range exceeds $20 \mathrm{~dB}$. The gray areas show the ranges that will be considered as normal in evaluating the data for impaired listeners. Because the set of normal data is relatively large, comprising a total of 17 functions, the two extreme values at any level have been excluded from these "standard" normal ranges. Even with this trimming the standard normal ranges are considerable; at moderate levels they range from about 12 to well over $30 \mathrm{~dB}$ of temporal integration. At low and high SPLs, the standard normal range is much narrower, ranging from 7 or $8 \mathrm{~dB}$ to

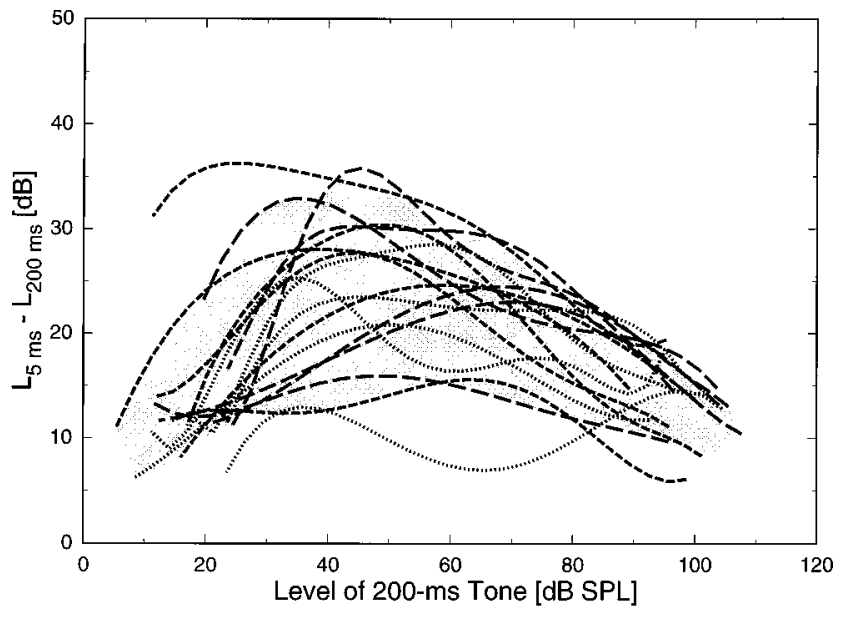

FIG. 3. The amount of temporal integration for loudness is plotted as a function of the SPL of the 200-ms tone. Each line shows the data obtained for a normal listener tested at 0.5 (long-dashed lines), 1 (short-dashed lines), or $4 \mathrm{kHz}$ (dotted lines). The gray area indicates a normal range that will be used as a "standard" against which impaired listeners' data can be evaluated. It encompasses the range from the second lowest to the second highest amount of temporal integration.

about $13 \mathrm{~dB}$ (see Fig. 3); at high SLs it is also relatively narrow, ranging from about 8 to $17 \mathrm{~dB}$, but at low SLs it ranges from about 7 to $23 \mathrm{~dB}$ (see Fig. 4). Clearly, the amount of temporal integration varies widely among normal listeners.

The statistical analyses support these observations. A three-way (frequency $\times$ duration $\times$ listener) ANOVA for repeated measures of the thresholds for the listeners who were tested at all three frequencies showed significant effects of duration $[F(1,4)=1580, p \leqslant 0.0001]$ and listener $[F(4,60)$ $=270.5, p \leqslant 0.0001]$, as well as significant interactions of listener and frequency $[F(8,60)=78.01, p \leqslant 0.0001]$ and of listener, frequency, and duration $[F(8,60)=7.59$, $p \leqslant 0.0001]$. No effect of frequency and no interaction between frequency and duration were present. These findings indicate that thresholds differ among listeners and are higher for the 5-ms tones than for the 200-ms tones. On the average, the thresholds do not differ among the three frequencies, but they differ among listeners and among frequencies within

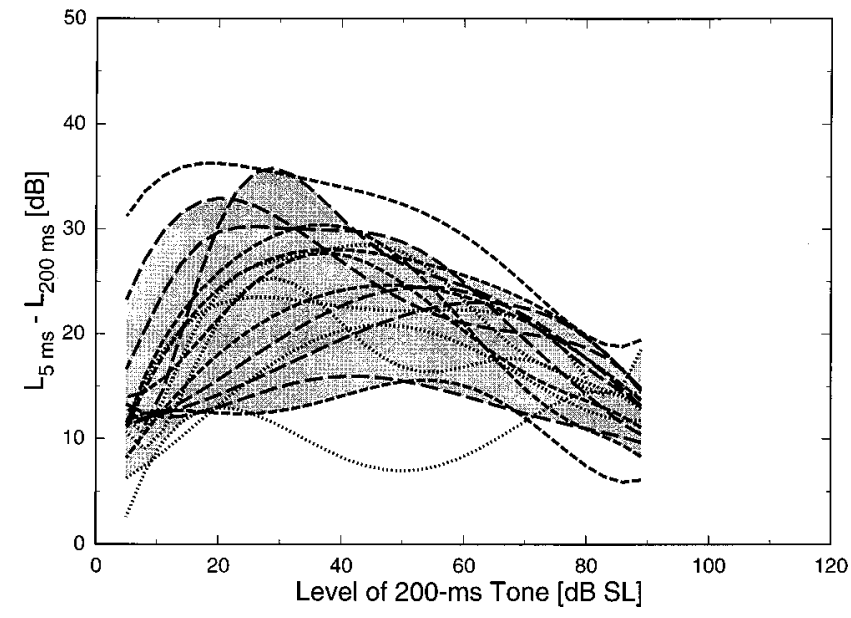

FIG. 4. Same as Fig. 3, except that the amount of temporal integration is plotted as a function of the 200-ms tone's sensation level, SL. 
TABLE II. Four-way analysis of variance for repeated measures of loudness matches by the five normal listeners who were tested at all three frequencies. The dependent variable is the level difference between the short and the long tone when they were judged to be equally loud. The stimulus variables frequency (Frq; 3 levels: $0.5,1$, and $4 \mathrm{kHz}$ ), sensation level (SL; 12 levels: 5,10,15,20,25,30,40,..,90 dB SL), and variable (Var; 2 levels: short varied or long varied) are fixed factors. Listener (Lsr; 5 levels: N1 through N5) is a random factor.

\begin{tabular}{lrrcrcc}
\hline \hline Source & \multicolumn{2}{c}{$\begin{array}{c}\text { Error } \\
d f\end{array}$} & $\begin{array}{c}\text { Sums of } \\
\text { squares }\end{array}$ & Mean square & $F$-ratio & Prob \\
\hline Const & 1 & 4 & 371191 & 371191 & 98.99 & 0.0006 \\
Frq & 2 & 8 & 2309 & 1155 & 2.630 & 0.13 \\
SL & 11 & 44 & 16879 & 1534 & 7.320 & $\leqslant 0.0001$ \\
Frq $\times$ SL & 22 & 87 & 1306 & 59.37 & 1.629 & 0.058 \\
Var & 1 & 4 & 160.4 & 160.4 & 10.12 & 0.034 \\
Frq $\times$ Var & 2 & 8 & 22.08 & 11.04 & 0.4471 & 0.65 \\
SL $\times$ Var & 11 & 44 & 3754 & 341.3 & 9.133 & $\leqslant 0.0001$ \\
Frq $\times$ SL $\times$ Var & 22 & 87 & 492.3 & 22.38 & 1.339 & 0.17 \\
Lsr & 4 & 716 & 14999 & 3749 & 226.1 & $\leqslant 0.0001$ \\
Frq $\times$ Lsr & 8 & 716 & 3512 & 439.1 & 26.47 & $\leqslant 0.0001$ \\
SL $\times$ Lsr & 44 & 716 & 9223 & 209.6 & 12.64 & $\leqslant 0.0001$ \\
Frq $\times$ SL $\times$ Lsr & 87 & 716 & 3171 & 36.45 & 2.198 & $\leqslant 0.0001$ \\
Var $\times$ Lsr & 4 & 716 & 63.42 & 15.85 & 0.9560 & 0.43 \\
Frq $\times$ Var $\times$ Lsr & 8 & 716 & 197.6 & 24.70 & 1.489 & 0.16 \\
SL $\times$ Var $\times$ Lsr & 44 & 716 & 1644 & 37.37 & 2.253 & $\leqslant 0.0001$ \\
Frq $\times$ SL $\times$ Var $\times$ Lsr & 87 & 716 & 1454 & 16.71 & 1.007 \\
Error & 716 & & 11874 & 16.59 & & 0.46 \\
Total & 1073 & & 79641 & & & \\
\hline \hline
\end{tabular}

listeners. The average amounts of temporal integration differ neither across frequency nor among listeners, but highly reliable differences in temporal integration across frequency are present within listeners.

Table II shows the results of the ANOVA for the amounts of temporal integration calculated from the loudness-balance data. The top half shows the significance of stimulus effects and the bottom half shows the significance of differences among listeners. Frequency and all interactions with it are not significant. This finding indicates that no consistent effect of frequency is present in the data. In contrast, the effect of SL is highly significant, which reflects the nonmonotonic effect of level on the amount of temporal integration for loudness. The effect of variable (5- or 200-ms tone varied) and the interaction between SL and variable are also significant. These findings indicate that equal SL does

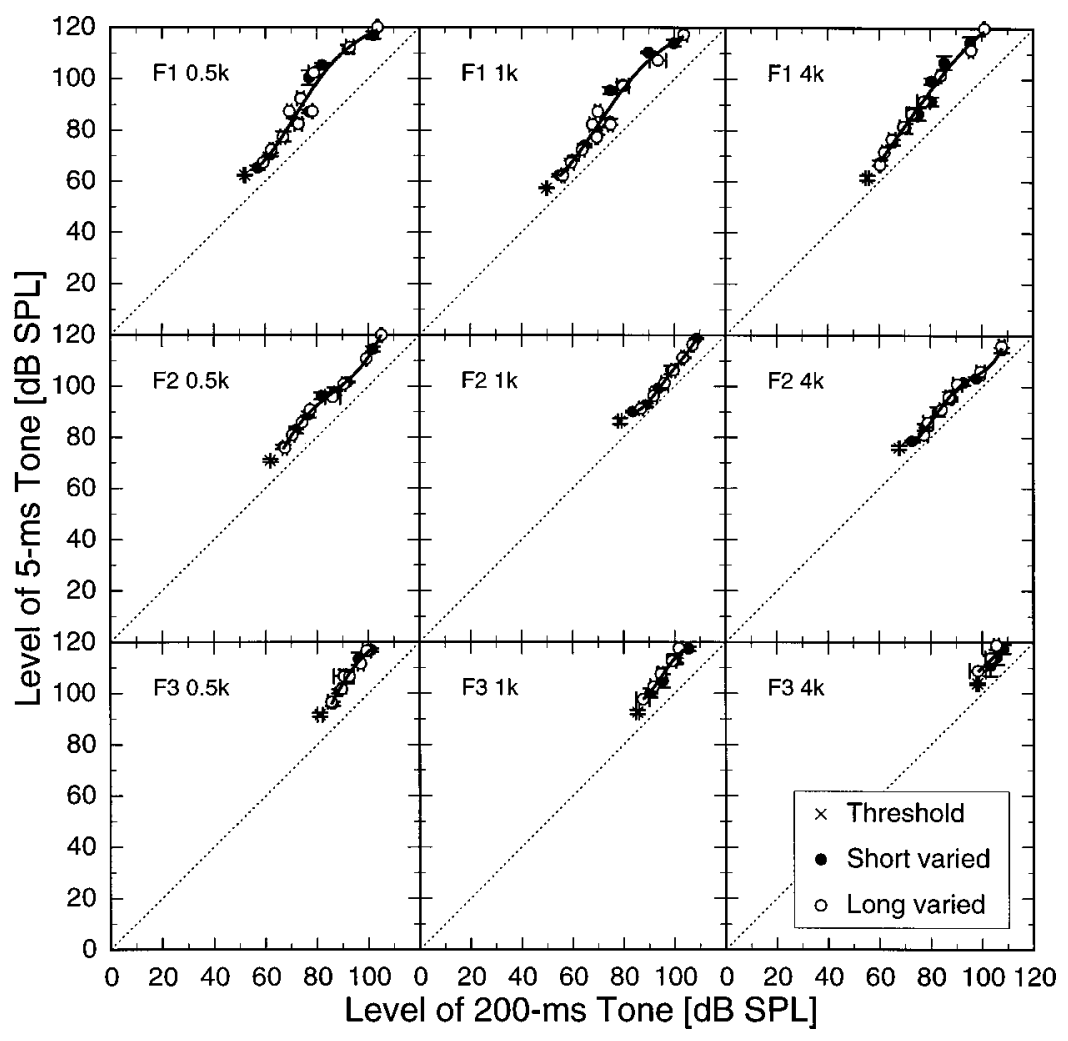

FIG. 5. Same as Fig. 1, but for three listeners with flattish hearing losses. 


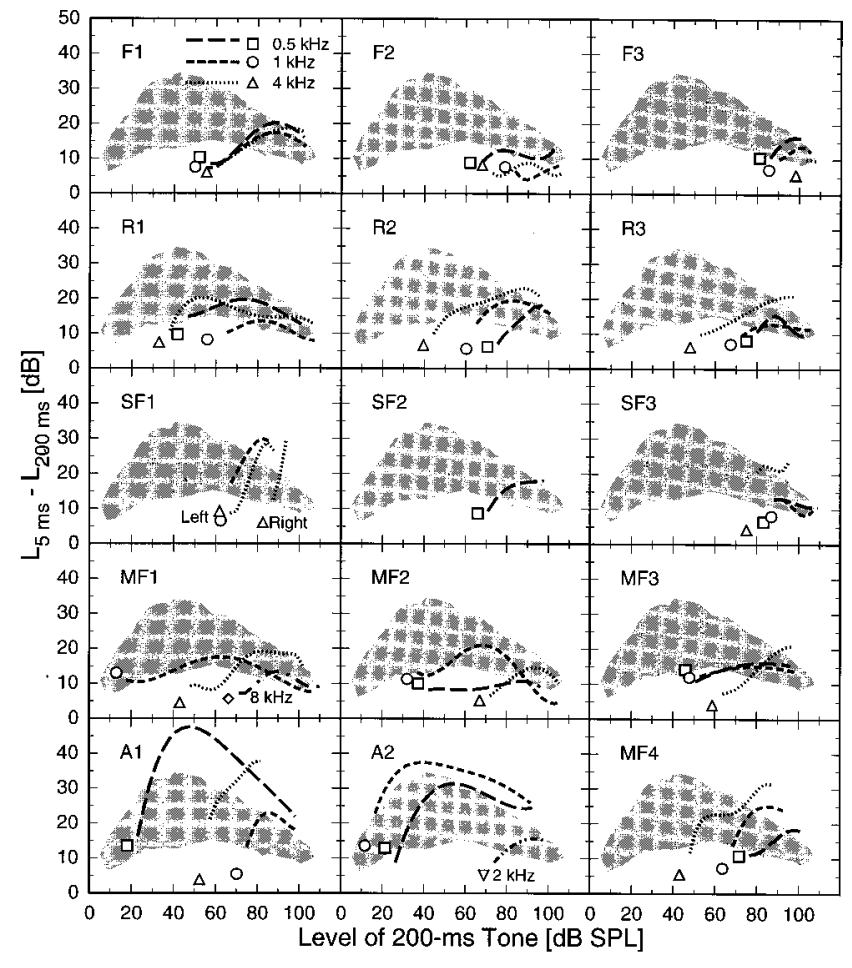

FIG. 6. The amount of temporal integration for loudness obtained for 15 listeners with impairments of predominantly cochlear origin plotted in the same manner as Fig. 2. The gray area in each panel indicates the standard normal range for the amount of temporal integration as a function of SPL (see Fig. 3). Except for the bottom row, each row shows data for listeners with different overall audiometric configurations (see Sec. I D for the classification criteria). Data for flattish audiograms are shown in the top row, rising audiograms in the second row, moderately severe and severe losses with falling audiograms in the third row, and mild-to-moderate losses with falling audiograms in the fourth row. The bottom row shows data for two listeners with high-frequency losses and abruptly falling audiograms and for the fourth listener with a mild-to-moderate loss and a falling audiogram. Labels by selected functions in the panels for SF1, MF1, and A2 designate test conditions that cannot be identified from the legend in the top-left panel.

not yield equal loudness for short and long tones. Loudness balances with the short tone fixed at some SL are performed at a different loudness level than those with the long tone fixed at the same SL, and the results obtained in the two conditions differ because the amounts of temporal integration depend on loudness level. The bottom half of the table shows that the effects of frequency, SL, and the interaction between frequency and SL vary among listeners. These findings indicate that individual listeners show highly reliable differences in the form of their temporal-integration functions at different frequencies, but as noted above the differences are not consistent across listeners.

Additional analyses of covariance (ANCOVAs) showed that the maximal amount of temporal integration for loudness was uncorrelated with the level at which it occurred, the listeners' threshold at the test frequency, and their temporal integration for detection. Likewise, the level at which the maximal amount of temporal integration occurred was uncorrelated with both the threshold for the 200-ms tone and with the amount of temporal integration for detection. However, a two-way ANCOVA (age $\times$ frequency) revealed that the maximal amount of temporal integration for loudness increased significantly with age $[F(1,11)=7.06, p=0.022)]$, whereas there was no significant effect of age on the level at which the maximum occurred. The effect of age on the maximal amount of temporal integration for loudness is surprising and may be a spurious result caused by the relatively small amounts of temporal integration obtained for listener N5, who was the second youngest of the normal listeners.

\section{B. Listeners with cochlear impairments}

To provide an example of the data obtained for impaired listeners, Fig. 5 shows the loudness matches obtained for the three listeners with flattish hearing losses. The impaired listeners' judgments were usually very consistent, as indicated by the small error bars. The average standard error for the data in Fig. 5 was $1.3 \mathrm{~dB}$. (The average standard error for all the impaired listeners' data was slightly larger, $1.6 \mathrm{~dB}$, but was still smaller than that obtained for the trained normal listeners.) As for the normal listeners, the data obtained with the 5-ms tone varied and with the 200-ms tone varied generally lie on a single smooth function, except that the data for listener F1 show some separation between the low- and highlevel segments of the functions, qualitatively similar to the separation observed in some normal listeners. For this listener, $25 \mathrm{~dB}$ SL was included in both sets. The results were the same in both sets when the $4-\mathrm{kHz}$ long tone was varied, but the remaining data at $25 \mathrm{~dB}$ SL show $10 \mathrm{~dB}$ more temporal integration in the high than in the low set. Listener F2 had $20 \mathrm{~dB}$ SL included in both the low and high sets at 4 $\mathrm{kHz}$ and listener F3 had $15 \mathrm{~dB}$ SL included in both sets at 0.5 and $1 \mathrm{kHz}$. No discrepancy between the low and high sets is apparent in these conditions.

Despite the occasional deviations between the low and high sets, the fitted polynomials generally summarize the data quite accurately, as shown by the solid lines. Across all the impaired listeners (a total of 43 functions), the average $r^{2}$ is 0.962 . The range of $r^{2}$ is 0.910 to 0.998 , except that two functions yielded $r^{2}$ of $0.720(\mathrm{~F} 3$ at $4 \mathrm{kHz})$ and $0.876(\mathrm{MF} 2$ at $0.5 \mathrm{kHz}$ ). The low correlation for $\mathrm{F} 3$ at $4 \mathrm{kHz}$ is a result of her six data points encompassing only about a $10-\mathrm{dB}$ range of levels. The low correlation for MF2 at $0.5 \mathrm{kHz}$ results because he shows a relatively large range effect and his data encompassed only about a 55-dB range of levels.

Figure 6 shows the amount of temporal integration as a function of SPL for all the impaired listeners plotted in the same manner as Fig. 2. For comparison, the "standard" normal range from Fig. 3 is shown together with the data for each listener. The amounts of temporal integration for detection by the impaired listeners range from 4 to $14 \mathrm{~dB}$ and are mostly lower than those for the normal listeners. Generally, the amount of temporal integration for detection appears less than normal whenever the threshold is elevated. Listener MF3 at $0.5 \mathrm{kHz}$ is the only exception. The impaired listeners' average amounts of temporal integration for detection are $10.0 \mathrm{~dB}$ at $0.5 \mathrm{kHz}, 8.6 \mathrm{~dB}$ at $1 \mathrm{kHz}$, and $6.0 \mathrm{~dB}$ at 4 $\mathrm{kHz}$; these values are about $5 \mathrm{~dB}$ lower than those for normal listeners.

The amounts of temporal integration for loudness vary even more for the impaired than for the normal listeners. As for normal listeners, no obvious trend across frequency is apparent and the amount of temporal integration for loudness 


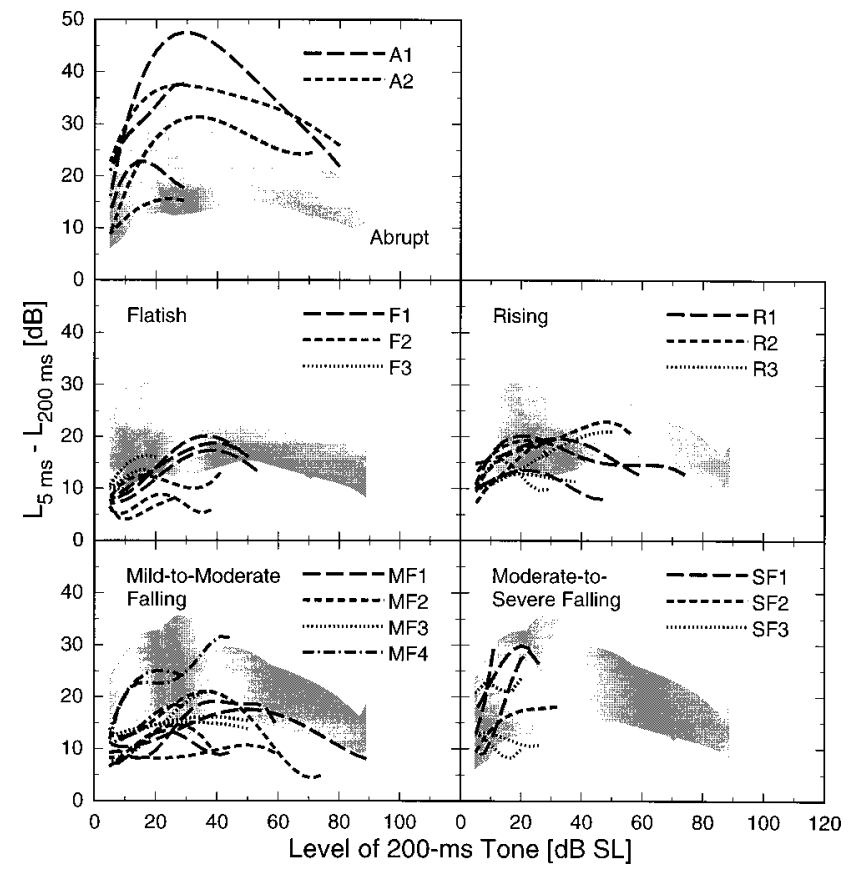

FIG. 7. The amount of temporal integration for loudness as functions of SL in the 15 impaired listeners is plotted in separate panels for each audiometric group. The gray area shows the standard normal range for the amount of temporal integration as a function of SL (see Fig. 4).

at low sensation levels generally approaches that obtained for detection, but a few exceptions may be present (e.g., A1 and SF3 at $4 \mathrm{kHz}$ ). For the majority of listeners and frequencies, the amount of temporal integration varies nonmonotonically with level and is largest at some moderately low sensation level. As the level increases above $5 \mathrm{~dB} \mathrm{SL}$, the amount of temporal integration usually increases, often dramatically. The maximal amounts of temporal integration vary from $9(\mathrm{~F} 2$ at $4 \mathrm{kHz} ; 8 \mathrm{~dB}$ if the maximum of F2's $1-\mathrm{kHz}$ function is used, but this function does not appear to reach its maximum within the range of levels tested) to 48 $\mathrm{dB}(\mathrm{A} 1 \mathrm{at} 0.5 \mathrm{kHz})$. The averages of the maxima are $20 \mathrm{~dB}$ ( $\pm 9.7 \mathrm{~dB}$ standard deviation) at $0.5 \mathrm{kHz}, 20 \mathrm{~dB}$ at $1 \mathrm{kHz}$ $( \pm 7.4 \mathrm{~dB})$, and $21 \mathrm{~dB}( \pm 8.4 \mathrm{~dB})$ at $4 \mathrm{kHz}$. These averages are $7 \mathrm{~dB}$ lower than normal at 0.5 and $1 \mathrm{kHz}$, and $1 \mathrm{~dB}$ lower than normal at $4 \mathrm{kHz}$. The maximal amount of temporal integration for loudness in impaired listeners does not appear related to the level (SPL or SL) at which it occurs or to the detection threshold, if the data for the listeners with abrupt losses are omitted. It also appears unrelated to the amount of temporal integration for detection. On the other hand, the SPL at which the maximum occurs generally increases with the threshold, whereas the SL of the maximum decreases as the threshold increases.

Except near threshold, the impaired listeners' amounts of temporal integration usually are within the normal range, and at high SPLs they exceed the top of the normal range in about half the conditions tested. A few impaired listeners are clearly different from normal. Listener F2 shows less-thannormal amounts of temporal integration for loudness at almost all SPLs, and the two listeners with abrupt losses, A1 and A2, have obviously abnormal temporal-integration functions. As shown in the bottom row of Fig. 6, these listeners yield larger-than-normal amounts of temporal integration at the frequencies just below their abrupt losses $(0.5 \mathrm{kHz}$ for $\mathrm{A} 1$ and $1 \mathrm{kHz}$ for $\mathrm{A} 2$ ). The maximal amount of temporal integration for $\mathrm{A} 1$ is nearly $48 \mathrm{~dB}$, which is more than $11 \mathrm{~dB}$ above the largest amount of temporal integration obtained for any normal listener at any frequency. A large maximum is also obtained for listener A1 at $4 \mathrm{kHz}$ and for listener A2 at $0.5 \mathrm{kHz}$. In summary, once the level is somewhat above threshold, the impaired listeners usually show amounts of temporal integration for loudness that are as large as, or sometimes even larger than, that obtained for normal listeners tested at the same SPL. The normal or larger-than-normal temporal integration for loudness contrasts with impaired listeners' reduced temporal integration for detection. As discussed below, this contrast may indicate that the comparison between normal and impaired listeners depends on whether it is made at equal SPLs or equal SLs, because the data for detection necessarily represent an equal-SL comparison.

Whereas the amounts of temporal integration at high SPLs are larger than normal in about half the conditions tested when normal and impaired listeners are compared at equal SPLs, the tendency towards abnormally large temporal integration disappears almost completely if the comparison between normal and impaired listeners is made at equal SLs. This is illustrated in Fig. 7, which shows the amounts of temporal integration obtained for the impaired listeners plotted as a function of SL. Only five functions have segments above the standard normal area. Four of those come from the listeners with abrupt losses. The fifth function is for MF4 at $4 \mathrm{kHz}$. It exceeds the normal range for a few $\mathrm{dB}$ near the highest SLs. On the other hand, 16 of the 43 functions have segments that fall below the normal range, and the central tendency is clearly towards the low end of the normal range for the groups with flattish, rising, and mild-to-moderate falling audiometric configurations. Thus, it appears that when normal and impaired listeners are compared at equal SLs, the amounts of temporal integration are generally normal or, for some groups, slightly less than normal. The clearest exception is listeners with abrupt hearing losses, who show unusually large amounts of temporal integration for loudness whether the comparison to normal listeners is at equal SPL or equal SL.

The preceding figures showed the results with listeners divided according to the overall configuration of their audiograms. Apart from the two listeners with abrupt losses, no clear differences among the groups were apparent. One might hypothesize that a clearer separation among the temporal-integration functions could be obtained by considering the course of the hearing loss above the test frequency. This hypothesis follows from findings that the amount of temporal integration appears to be related to the slope of the loudness function (Florentine et al., 1996, 1998; Buus et al., 1997) and that the growth of loudness depends to some extent on upward spread of excitation (e.g., Hellman, 1974; Florentine et al., 1997). However, grouping the temporalintegration functions according to the local shape of the audiogram as defined by the change in hearing loss over one (for the 4-kHz functions) or two octaves (for lower frequencies) above the test frequency did not improve the order of 
TABLE III. Four-way analysis of variance for loudness matches by all the listeners grouped according to the overall configuration of their audiograms. The dependent variable is the level difference between the short and the long tone when they were judged to be equally loud. The independent variables sensation level (SL; 7 levels: 5, 10, 15, 20, 25, 30, and $40 \mathrm{~dB} \mathrm{SL}$ ), frequency (Frq; 3 levels: 0.5, 1, and $4 \mathrm{kHz}$ ), variable (Var; 2 levels: short varied or long varied), and audiometric group (AGp; 5 levels: normal, abrupt, falling, flatish, and rising) are fixed factors.

\begin{tabular}{|c|c|c|c|c|c|}
\hline Source & $d f$ & $\begin{array}{l}\text { Sums of } \\
\text { squares }\end{array}$ & Mean square & $F$-ratio & Prob \\
\hline Const & 1 & 596837 & 596837 & 16803 & $\leqslant 0.0001$ \\
\hline SL & 6 & 18369 & 3061 & 86.19 & $\leqslant 0.0001$ \\
\hline Frq & 2 & 190.2 & 95.12 & 2.678 & 0.069 \\
\hline $\mathrm{SL} \times$ Frq & 12 & 237.3 & 19.78 & 0.5568 & 0.88 \\
\hline Var & 1 & 1386 & 1386 & 39.01 & $\leqslant 0.0001$ \\
\hline $\mathrm{SL} \times \operatorname{Var}$ & 6 & 731.1 & 121.9 & 3.431 & 0.0023 \\
\hline Frq $\times$ Var & 2 & 65.66 & 32.83 & 0.9243 & 0.40 \\
\hline $\mathrm{SL} \times$ Frq $\times$ Var & 12 & 304.5 & 25.38 & 0.7145 & 0.74 \\
\hline $\mathrm{AGp}$ & 4 & 20682 & 5170 & 145.6 & $\leqslant 0.0001$ \\
\hline $\mathrm{SL} \times \mathrm{AGp}$ & 24 & 3941 & 164.2 & 4.623 & $\leqslant 0.0001$ \\
\hline Frq $\times A G p$ & 8 & 3863 & 482.8 & 13.59 & $\leqslant 0.0001$ \\
\hline $\mathrm{SL} \times$ Frq $\times A G p$ & 48 & 1978 & 41.21 & 1.160 & 0.21 \\
\hline Var×AGp & 4 & 986.5 & 246.6 & 6.943 & $\leqslant 0.0001$ \\
\hline $\mathrm{SL} \times \operatorname{Var} \times \mathrm{AGp}$ & 24 & 749.4 & 31.23 & 0.8791 & 0.63 \\
\hline Frq $\times \operatorname{Var} \times A G p$ & 8 & 222.0 & 27.75 & 0.7811 & 0.62 \\
\hline $\mathrm{SL} \times \operatorname{Frq} \times \operatorname{Var} \times \mathrm{AG} p$ & 47 & 794.4 & 16.90 & 0.4758 & 1.00 \\
\hline Error & 2072 & 73598 & 35.52 & & \\
\hline Total & 2280 & 148392 & & & \\
\hline
\end{tabular}

the data appreciably. Whether the temporal-integration functions were compared at equal SPLs or at equal SLs, the consistency within classes was, at best, only slightly better than that obtained when listeners were grouped according to their overall audiometric configurations. Although this finding may seem counterintuitive, it agrees with the excitationpattern model for impaired listeners. Upward spread of excitation combined with abnormally fast growth of specific loudness can restore normal growth of loudness, even if the hearing loss limits the spread of excitation to only about one octave (Florentine et al., 1997).

The statistical analyses are consistent with the observations on the SL data. As shown in Table III, the ANOVA showed significant effects of SL and variable (short or long), and a significant interaction of variable and SL. The first effect indicates that the amount of temporal integration varies with sensation level for both normal and impaired listeners and generally increases with SL over the 5-to-40-dB range included in the analysis. The latter effects most likely reflect the findings that short and long stimuli at equal SL generally are not equally loud and that different amounts of temporal integration are obtained at different loudness levels. In addition to these stimulus effects, the effect of overall audiometric configuration and all two-way interactions with the stimulus variables are significant. Some of these effects undoubtedly reflect effects of hearing loss, but because the hearing-impaired groups consist of two to four listeners, the effects may also reflect interlistener differences, which are large.

The Scheffé post hoc tests for contrast showed highly significant differences among the groups. Averaged over all stimulus conditions included in the analysis, the listeners with abrupt losses showed significantly larger amounts of temporal integration than the normal listeners, whose tempo- ral integration was larger than those for the rising and falling losses. The latter two groups did not differ significantly, but their amounts of temporal integration were significantly larger than those for the listeners with flattish losses. The interactions with SL, frequency, and variable show that the differences among listeners depended somewhat on these stimulus variables, but significant differences similar to those between the grand means for each group were present for a number of SLs and at most frequencies.

Additional ANCOVAs on the effects of frequency, threshold for the 200-ms tone, and age on the impaired listeners' amounts of temporal integration for detection showed a significant effect of frequency $[F(2,29)=3.568, p=0.041]$ and a significant interaction between the threshold for the 200 -ms tone and frequency $[F(2,29)=3.505, p=0.043]$. The effects of age and interactions with it were not significant. To explore the interaction between the threshold for the 200-ms tone and frequency, separate ANCOVAs were performed on the relation between the threshold and the amount of temporal integration. These analyses showed that the amount of temporal integration decreased significantly as the threshold increased at $0.5[F(1,11)=28.58, p=0.0002]$ and $1 \mathrm{kHz}$ $[F(1,12)=10.88, p=0.0064]$, whereas the relation did not reach significance at $4 \mathrm{kHz}$.

An ANCOVA of the impaired listeners' maximal amount of temporal integration of loudness showed no significant dependence on frequency, the threshold for the 200-ms tone, or the SPL at which the maximum occurred when the listeners with abrupt losses were excluded from the analysis. (The low thresholds and large amounts of temporal integration obtained for the abrupt losses at low frequencies produced significant effects of the threshold and SPL at which the maximum occurred.) On the other hand, the SPL at which the maximal amount of temporal integration oc- 
curred increased significantly with the threshold for the 200-ms tone at the test frequency, whether the abrupt-loss listeners were included $[F(1,35)=74.86, p \leqslant 0.0001]$ or not $[F(1,30)=34.68, p \leqslant 0.0001]$, and the SL at which the maximum occurred decreased significantly as the threshold for the 200-ms tone increased both with $[F(1,35)=43.39$, $p \leqslant 0.0001]$ and without $[F(1,30)=63.74, p \leqslant 0.0001]$ the abrupt-loss listeners.

\section{DISCUSSION}

\section{A. Comparison with other data}

The present data for normal hearing are in good agreement with data from previous studies (Florentine et al., 1996, 1998) that used $1-\mathrm{kHz}$ tones with the same temporal parameters as those in the present study. The average amount of temporal integration at $5 \mathrm{~dB}$ SL was about $13 \mathrm{~dB}$ in the present study, similar to the values of about $12 \mathrm{~dB}$ obtained by Florentine et al. (1996) and $15 \mathrm{~dB}$ obtained by Florentine et al. (1998). Likewise, the amount of temporal integration obtained at $90 \mathrm{~dB}$ SPL in the present study was $13 \mathrm{~dB}$, which is close to the $11 \mathrm{~dB}$ reported by Florentine et al. (1996) and $14 \mathrm{~dB}$ reported by Florentine et al. (1998). The maximal amount of temporal integration of the average data was 26 $\mathrm{dB}$ in the present study, which is close to the maximum of 27 dB obtained by Florentine et al. (1998) but somewhat larger than the $18 \mathrm{~dB}$ obtained by Florentine et al. (1996). Given that the individual listeners in the three studies show maxima varying from about 12 to about $36 \mathrm{~dB}$, it is not surprising that the maximal amounts of temporal integration vary somewhat across studies. [It should be noted that $\mathrm{N} 1$ and N3 also were tested by Florentine et al. (1996). The maximal amounts of temporal integration for these listeners at $1 \mathrm{kHz}$ are about $5 \mathrm{~dB}$ larger in the present than in the previous experiment. This discrepancy may reflect differences between the roving-level procedure used in the present experiment and the fixed-level procedure used by Florentine $e t a l$. (1996).]

The only previous data for impaired listeners are difficult to compare directly with the present data because comparisons between tones of widely different durations were only made indirectly. Pedersen and Poulsen (1973) varied only the shorter tone in a pair and the durations of the tones always differed by a factor of 2 . The total amount of temporal integration between 5- and 320-ms tones was estimated by adding the level differences measured for all the pairs between these durations. Whereas this procedure makes the listeners' judgments relatively easy, the estimates of the total amount of temporal integration are susceptible to accumulation of systematic biases. At high levels, the variable tone typically is set to a level slightly below that required for equal loudness (e.g., Stevens, 1955; Scharf, 1961; Port, 1963; Florentine et al., 1996), which would cause the amount of temporal integration to be underestimated when only the short tone is varied. Thus, it is not surprising that the amounts of temporal integration reported by Pedersen and Poulsen (1973) are smaller than those obtained in the present study. Nevertheless, the present study is qualitatively consistent with the previous study in that both found a ten- dency towards larger amounts of temporal integration in impaired listeners than in normal listeners when the groups are compared at equal, high SPLs. However, when normal and impaired listeners are compared at equal SLs, the amount of temporal integration for impaired listeners tends to be in the low end of the normal range, except when the hearing loss is abrupt (see Fig. 7). Indeed, the amount of temporal integration for detection (i.e., at $0 \mathrm{~dB} \mathrm{SL}$ ) generally is reduced when the threshold is elevated by cochlear hearing losses, as has been shown by many previous studies (for review, see Florentine et al., 1988), as well as in the present study.

It also may be instructive to compare the effects of hearing impairment on temporal integration of loudness to those of partial masking, because it often has been suggested that partial masking increases the rate of loudness growth near masked threshold in a manner similar to the abnormally fast growth of loudness that is typical of listeners with cochlear hearing losses (e.g., Steinberg and Gardner, 1937; Richards, 1973; see also Florentine and Buus, 1986; Buus and Florentine, 1989). Two studies have measured temporal integration of loudness under partial masking (Richards, 1977; Florentine et al., 1998). Although neither study aimed to simulate any particular impaired listener, qualitative comparisons may be made with the present study. Both studies of partial masking found that temporal integration at high levels was unaffected by the presence of a masker, which is similar to the finding that the amount of temporal integration for most impaired listeners tested at high SPLs is equal to or slightly larger than that for normal listeners tested at the same SPLs. In addition, Florentine et al. (1998) found that the maximal amount of integration decreased and occurred at increasingly higher-tone SPLs as the masker level increased. The SL at which the maximum occurred decreased as the masker level increased. These findings are qualitatively similar to those for impaired listeners. The present study shows that the maximal amount of temporal integration tends to be smaller in impaired listeners than in normal listeners, except in cases of abrupt loss. The SPL at which the maximum occurs increases as the hearing loss increases, but the SL decreases.

It should be noted that the present study did not find an orderly relation between the listeners' thresholds and their maximal amounts of temporal integration, contrary to the orderly decrease of the maximal amount of temporal integration with increasing masker level reported by Florentine et al. (1998). This difference between hearing loss and masking may be understood by considering the mechanisms of threshold elevation in the two cases. In Florentine et al.'s (1998) study, the threshold elevation was caused by onfrequency masking, which most likely is excitatory (Delgutte, 1990) and increases threshold by increasing the activity in the auditory channel tuned to the signal, thus requiring the signal to produce more activity before it can be heard. In any event, elevating the threshold by masking evokes a uniform mechanism of threshold elevation across listeners, and it is not surprising that an orderly relation is obtained between the amount of threshold elevation and the maximal amount of temporal integration, which reflects the shallowest slope of the loudness function, as explained later.

Cochlear hearing loss appears to involve two indepen- 


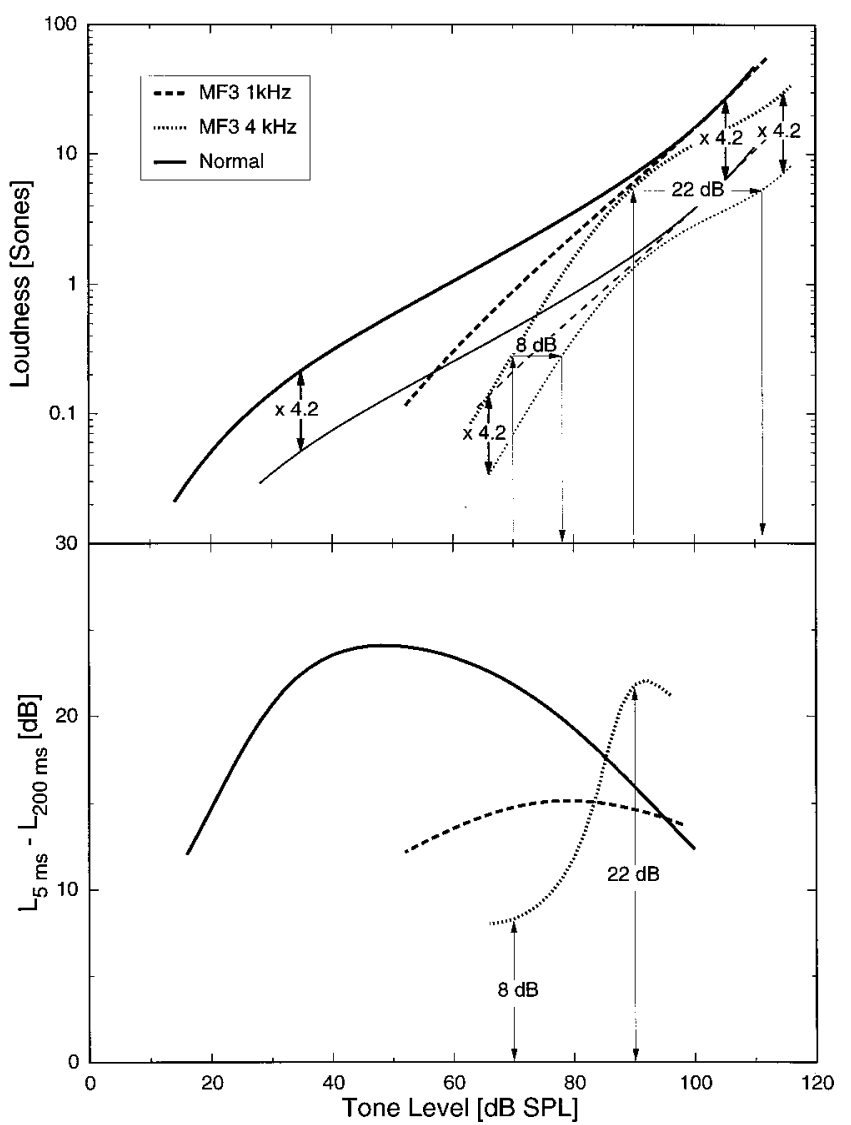

FIG. 8. Relation between the amount of temporal integration for loudness and the loudness function for normal and impaired listeners. The bottom panel shows the temporal-integration functions for normal listeners (averaged across listeners and frequencies; solid line) and for impaired listener MF3 at 1 (dashed line) and $4 \mathrm{kHz}$ (dotted line). The top panel shows loudness functions for 200-(thick lines) and 5-ms tones (thin lines) derived from these temporal-integration functions under the assumption that the ratio of their loudnesses is 4.2 at all SPLs both for normal listeners and for the impaired listener. The arrows to the dotted lines illustrate the application of the equal-loudness-ratio hypothesis to MF3's data. When the 200-ms tone is at $70 \mathrm{~dB}$ SPL, the amount of temporal integration is just over $8 \mathrm{~dB}$ and its loudness is just below 0.3 sones. The loudness of the 5-ms tone is 4.2 times less, or about 0.07 sones. To match the temporal-integration data, the loudness of the 5-ms tone must grow from 0.07 sones at $70 \mathrm{~dB}$ SPL to 0.3 sones at just over $78 \mathrm{~dB}$ SPL. This indicates that the loudness function must be quite steep; the exponent is about $10 \mathrm{~dB} \times \log (4.2) / 8 \mathrm{~dB}=0.79$. When the $200-\mathrm{ms}$ tone is at $90 \mathrm{~dB}$ SPL, the amount of temporal integration is near 22 $\mathrm{dB}$ and the loudness is about 5.5 sones. The loudness of the 5 -ms tone is again 4.2 times less, or about 1.3 sones. To match the temporal-integration data, the loudness of the 5-ms tone must grow from 1.3 sones at $90 \mathrm{~dB}$ to 5.5 sones at $112 \mathrm{~dB}$ SPL. This indicates that the loudness function must be rather shallow; the exponent is about $10 \mathrm{~dB} \times \log (4.2) / 22 \mathrm{~dB}=0.28$.

dent mechanisms of threshold elevation. One is a loss of transduction efficiency by the inner hair cells, which produces a loss that may be considered similar to an attenuation of the neural output (e.g., Florentine and Zwicker, 1979) or an attenuation of the acoustic signal (Patuzzi, 1993; Moore and Glasberg, 1997). In either case, the hearing loss does not change the form of the loudness function, but shifts it down along the loudness axis or to the right along the signal-level axis. The other mechanism is a loss of mechanical amplification of the basilar-membrane vibration by the outer-hair cells, which causes a loss of compression and alters the form of the loudness function (Yates, 1990b; Ruggero and Rich, 1991; Patuzzi, 1993; Moore and Glasberg, 1997). Because a given amount of hearing loss can result from different amounts of inner- and outer-hair-cell damage, the amount of alteration to the loudness function caused by a given amount of hearing loss can vary among listeners. Accordingly, it is not surprising that no orderly relation between the amount of hearing loss and the maximal amount of temporal integration is obtained in the present study.

In conclusion, it appears that the effects of partial masking on temporal integration of loudness are very similar to those of a typical cochlear impairment, but are much more orderly. The difference in orderliness probably occurs because masking involves a uniform mechanism of threshold elevation, whereas hearing loss involves two mechanisms that allow the effects of a given hearing loss to vary among listeners.

\section{B. Relation between temporal integration and growth of loudness in impaired listeners}

Previous papers suggested that a close relationship might exist between the temporal-integration function and the growth of loudness (Florentine et al., 1996, 1998; Buus et al., 1997). The relationship can be quantified by assuming that the ratio between the loudnesses of a long and a short tone of equal SPL is independent of the SPL. Although it has yet to be investigated whether this simple relation is strictly true across the entire dynamic range, the assumption of a constant-loudness ratio yields a relation between temporal integration and growth of loudness that appears very useful. If one assumes that the loudness of a 200-ms tone is, for example, four times the loudness of an equal-SPL 5-ms tone, the loudness functions for both tones can be derived from the temporal-integration function, except for a multiplicative constant. In other words, the equal-loudness-ratio hypothesis does not provide an estimate of the absolute loudness. Any pair of loudness functions for 5- and 200-ms stimuli plotted on a logarithmic scale of loudness may be moved vertically without losing consistency with the temporal-integration functions. This vertical movement is similar to the normalization generally applied to direct measurements of the loudness function by the method of magnitude estimation.

As shown in Fig. 8, the equal-loudness-ratio assumption means that the loudness functions for the 5- and 200-ms tones are parallel when they are plotted in the conventional manner with loudness on a logarithmic scale as a function of the SPL of the tone. That is, the vertical distance between the loudness functions is constant, owing to the assumption of a level-independent loudness ratio between them. The amount of temporal integration is the horizontal distance between the functions at some fixed loudness. Accordingly, the loudness functions must be steep when the amount of temporal integration is small, and shallow when it is large.

As illustrated by the arrows in the figure and explained in the caption, the equal-loudness-ratio hypothesis predicts that the slope of the loudness function is roughly inversely proportional to the amount of temporal integration. The proportionality constant depends on the vertical distance between the functions; that is, the value of the fixed-loudness ratio. The ratio is unknown because it depends on the durations of the short and long tones and on how loudness grows 
with duration. However, the fixed ratio can be estimated by requiring the loudness function obtained from the temporalintegration function of normal listeners to approximate the "standard" loudness function. For the loudness functions in Fig. 8 the ratio is 4.2 , which yields a normal loudness function close to Zwislocki's (1965) modified power function, except at high levels. As noted above, the vertical position of the loudness functions cannot be determined from the temporal-integration functions. The normal loudness functions in Fig. 8 are positioned to yield a monaural loudness of about 0.5 sones for a $200-\mathrm{ms}$ tone at $36 \mathrm{~dB}$ SL (corresponding to a binaural loudness of 1 sone at $40 \mathrm{~dB}$ SPL in the free field).

The solid lines in Fig. 8 shows the average normal temporal-integration function (lower panel) and the loudness function (upper panel) derived from it when the loudness ratio between 200- and 5-ms tones at equal SPLs is 4.2 at all SPLs. To maintain the constant vertical distance between the 5- and 200-ms loudness functions, they are steep when the amount of temporal integration is small, and shallow when it is large. The primary difference between the normal loudness function shown in Fig. 8 and the standard modified power function (Zwislocki, 1965) is that the former shows a steepening at high levels, because the amount of temporal integration decreases at high levels. It is noteworthy that the normal loudness function in Fig. 8 is at least qualitatively similar to the compressive transfer function used in the models of Moore, Oxenham, and colleagues (Moore et al., 1996; Oxenham and Moore, 1997; Oxenham et al., 1997; Moore and Oxenham, 1998). The loudness function derived from our temporal-integration measurements also shows features similar to the mechanical input/output function measured at the basilar membrane. The amplitude of basilar-membrane vibration grows more slowly with acoustic amplitude at moderate levels than at low and high levels (e.g., Robles et al., 1986; Yates, 1990a).

To explore the implications of the equal-loudness-ratio hypothesis for the present data, one may assume that the loudness ratio between equal-SPL 200- and 5-ms tones is the same in normal and in typical impaired listeners, as illustrated by the vertical arrows. If the equal-loudness-ratio hypothesis holds and if a typical hearing loss does not alter the loudness ratio between short and long tones, the similarities and differences between the normal and impaired temporalintegration functions should reflect similarities and differences between normal and impaired loudness-growth functions. This is illustrated by the broken lines in Fig. 8, which show temporal-integration functions (lower panel) and the corresponding loudness functions (upper panel) for listener MF3 at 1 (dashed lines) and $4 \mathrm{kHz}$ (dotted lines). Again, the vertical position of the loudness functions cannot be determined from the temporal-integration functions. The loudness functions for MF3 are positioned to yield close-to-normal loudness at high levels, consistent with complete recruitment. This position also is consistent with clinical estimates of her loudness function at $4 \mathrm{kHz}$. The horizontal distance between the normal loudness functions and MF3's loudness functions at $4 \mathrm{kHz}$ (that is, the gain required to produce normal loudness at $4 \mathrm{kHz}$ ) is within $2 \mathrm{~dB}$ of that estimated from category-scaling measurements of loudness functions for normal listeners and for MF3 in another laboratory.

As shown by the dotted line in the bottom panel, MF3's temporal-integration function at $4 \mathrm{kHz}$ showed a relatively small amount of temporal integration, just over $8 \mathrm{~dB}$, at 70 dB SPL (about $10 \mathrm{~dB}$ SL for the 200-ms tone). Because the vertical distance between the 5- and 200-ms loudness functions is fixed, her loudness functions must be quite steep to yield a horizontal distance of only $8 \mathrm{~dB}$. This is consistent with the recruitment that usually results from cochlear impairment. For high-SPL tones at $4 \mathrm{kHz}, \mathrm{MF} 3$ shows more temporal integration than normal listeners, which indicates that her loudness function may be shallower. Overall, MF3's data at $4 \mathrm{kHz}$ appear consistent with a loss of compression at low SLs whereas considerable compression may be present at levels above $90 \mathrm{~dB}$ SPL. In terms of excitation-pattern models of loudness in impaired listeners (Florentine and Zwicker, 1979; Moore and Glasberg, 1997), calculations indicate that all of her hearing loss is due to outer-hair-cell damage (Moore, personal communication).

The temporal-integration data for MF3 at $1 \mathrm{kHz}$ are quite different from those at $4 \mathrm{kHz}$. Near threshold and at high levels her amount of temporal integration is about 12 or $13 \mathrm{~dB}$, which is comparable to that obtained for normal listeners near threshold and around $95 \mathrm{~dB}$ SPL. However, MF3's data show only a very small effect of level on the amount of temporal integration, which causes the predicted loudness functions to be nearly perfect power functions. The loudness functions predicted for MF3 at $1 \mathrm{kHz}$ have about the same slope as the normal listeners' loudness functions near threshold, but are steeper than those for normal listeners at the same SPLs. This indicates that some recruitment is present. The slope at high levels is similar to normal when evaluated at equal SPLs, consistent with complete recruitment. Again, the loudness functions derived from MF3's temporal-integration data appear to indicate that her hearing loss is due to outer-hair-cell damage.

According to the excitation-pattern models of loudness in impaired listeners (Florentine and Zwicker, 1979; Moore and Glasberg, 1997), the form of impaired listeners' loudness functions can vary widely depending on the extent to which the hearing loss is due to damage of inner- or outerhair cells. According to the equal-loudness-ratio hypothesis, the form of the temporal-integration function changes with the form of the loudness function. Therefore, the wide variation of the temporal-integration functions obtained for the impaired listeners is likely to reflect varying proportions of inner- and outer-hair-cell damage. The dominant trends of the present data certainly seem to agree with expectations derived from the general properties of loudness growth in impaired listeners. The normal or slightly larger-than-normal temporal integration obtained for impaired listeners at high SPLs indicates that impaired listeners' loudness functions should have normal or slightly flatter-than-normal slopes at high levels. This seems consistent with measurements and theories of loudness in impaired listeners (e.g., MiskolczyFodor, 1960; Florentine and Zwicker, 1979; Florentine et al., 1997; Hellman and Meiselman, 1991; Moore and Glasberg, 1997), which typically show nearly normal growth of loud- 


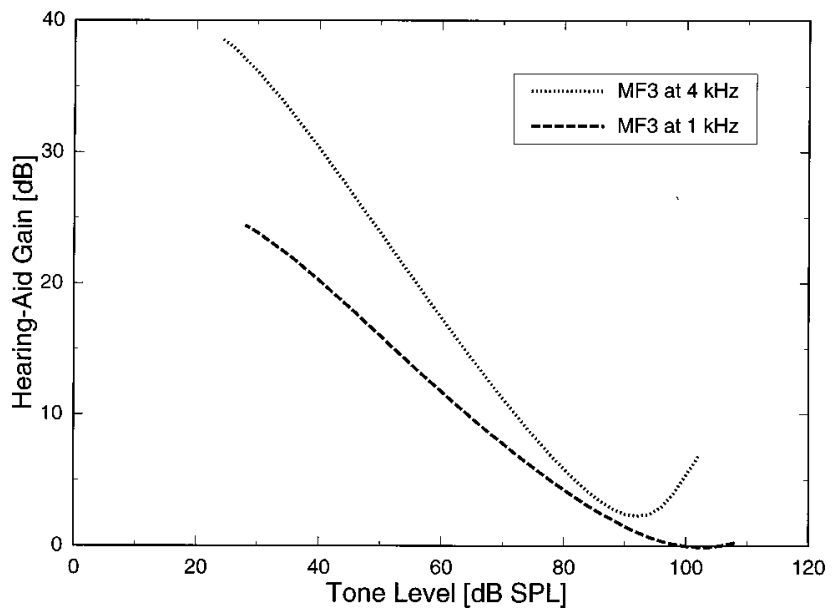

FIG. 9. Predicted hearing-aid gain necessary to restore normal loudness for listener MF3 is plotted as a function of input level for tones at 1 (dashed line) and $4 \mathrm{kHz}$ (dotted line). The predictions are identical for 5- and 200-ms tones.

ness in cochlear-impaired listeners tested at high levels, well above their elevated thresholds. Indeed, the excitationpattern model of loudness for impaired listeners can predict even shallower-than-normal loudness functions for impaired listeners at high levels (Moore, personal communication). Likewise, the tendency of most impaired listeners to show less-than-normal amounts of temporal integration at and near threshold is consistent with these listeners' steeper-thannormal growth of loudness for tones near threshold (e.g., Miskolczy-Fodor, 1960; Hellman and Meiselman, 1991; Moore and Glasberg, 1997).

The finding that maximal amounts of temporal integration tend to be smaller than normal in most impaired listeners indicates that the most compressive part of the loudness function is steeper in impaired than in normal listeners. This notion is consistent with the idea that cochlear impairments lead to a reduction or even complete loss of compression (Moore and Glasberg, 1997). Listeners with abrupt losses are an exception because their loudness functions are flatter than normal for frequencies close to the highest frequency of near-normal hearing (Hellman, 1994; Florentine et al., 1997; McDermott et al., 1998). Accordingly, one would expect listeners with abrupt losses to show larger-than-normal amounts of temporal integration at frequencies close to the onset of an abrupt loss. The present data for two listeners with abrupt losses fulfill this expectation.

\section{Implications for signal processing in hearing aids}

The loudness functions shown in Fig. 8 also have interesting implications for the design of hearing aids intended to restore impaired listeners' perception of loudness to normal. The gain required for loudness restoration may be estimated as the horizontal distance between the loudness function for normal listeners and that for the impaired listener. Figure 9 shows the hearing-aid gain estimated in this manner for MF3 at 1 and $4 \mathrm{kHz}$. The gain for $1-\mathrm{kHz}$ stimuli decreases steadily with increasing sound level to reach $0 \mathrm{~dB}$ at high levels. This estimate is consistent with the notion that wide-dynamicrange compression is best suited to restore impaired listen- ers' loudness growth (Barfod, 1978; Killion, 1993). The gain function for $4-\mathrm{kHz}$ stimuli is within $2 \mathrm{~dB}$ of that derived from clinical category-scaling measurements obtained for MF3, as noted in the discussion of the loudness functions in Fig. 8. This gain function also decreases for input levels up to just over $90 \mathrm{~dB}$ SPL, but increases somewhat at higher levels due to the apparent compression in MF3's 4-kHz loudness function at high levels. Despite the departure from constant gain at high levels, the $4-\mathrm{kHz}$ gain function is reasonably close to that provided by a hearing aid with widedynamic-range compression. The findings of gain functions consistent with those derived from other measurements of loudness in impaired listeners indicate that the temporalintegration data for impaired listeners are likely to reflect the properties of their loudness functions and a levelindependent loudness ratio between long and short tones.

Clinical loudness measurements used to estimate suitable gain characteristics for hearing aids usually employ tones of relatively long durations, such that the gain functions may be most appropriate for long-duration stimuli. Although many natural sounds are characterized by brief periods of relatively high intensity surrounded by periods of lower intensity, little consideration has been given to producing the appropriate gain for brief stimuli. The present data for temporal integration together with the equal-loudnessratio hypothesis provide estimates of loudness functions for both long and short stimuli, and allow gain functions for both to be derived. If the loudness ratio between long and short stimuli is the same in normal and impaired listeners, the normal and impaired loudness functions for short stimuli are displaced vertically from those for long stimuli by the same amount. Accordingly, the horizontal distances are maintained, which results in the prediction that the gain required to restore loudness of a sound of a given SPL is the same for long and short stimuli.

The requirement of identical gain for short and long stimuli with the same SPL can be approximated if a fast attack time is used for the compression hearing aid. To produce normal temporal variation in the loudness, a fast release time may also be desirable. However, compression schemes in which both the attack and the release are fast reduce the modulation depth of time-varying stimuli. Such a reduction in modulation depth may be undesirable because impaired listeners' sensitivity to amplitude modulation generally is similar to or worse than normal (e.g., Bacon and Viemeister, 1985; Hall and Grose, 1989; Bacon and Gleitman, 1992; Moore et al., 1992). Moreover, the overall loudness of a time-varying sound often is close to the loudness of its peaks (Fastl, 1975; Zwicker, 1977, 1984; Zwicker and Fastl, 1990; Zhang and Zeng, 1997). [The overall loudness may be closer to the average loudness when the modulation depth is moderate (Moore et al., 1998), but in this case the difference between the average loudness and the peak loudness is relatively small.] Thus, compression with a fast attack time may be sufficient to produce near-normal loudness in impaired listeners, and it is unclear whether a fast release time is necessary or even desirable.

The prediction of identical gains for long and short stimuli resulted from the assumption that hearing impairment 


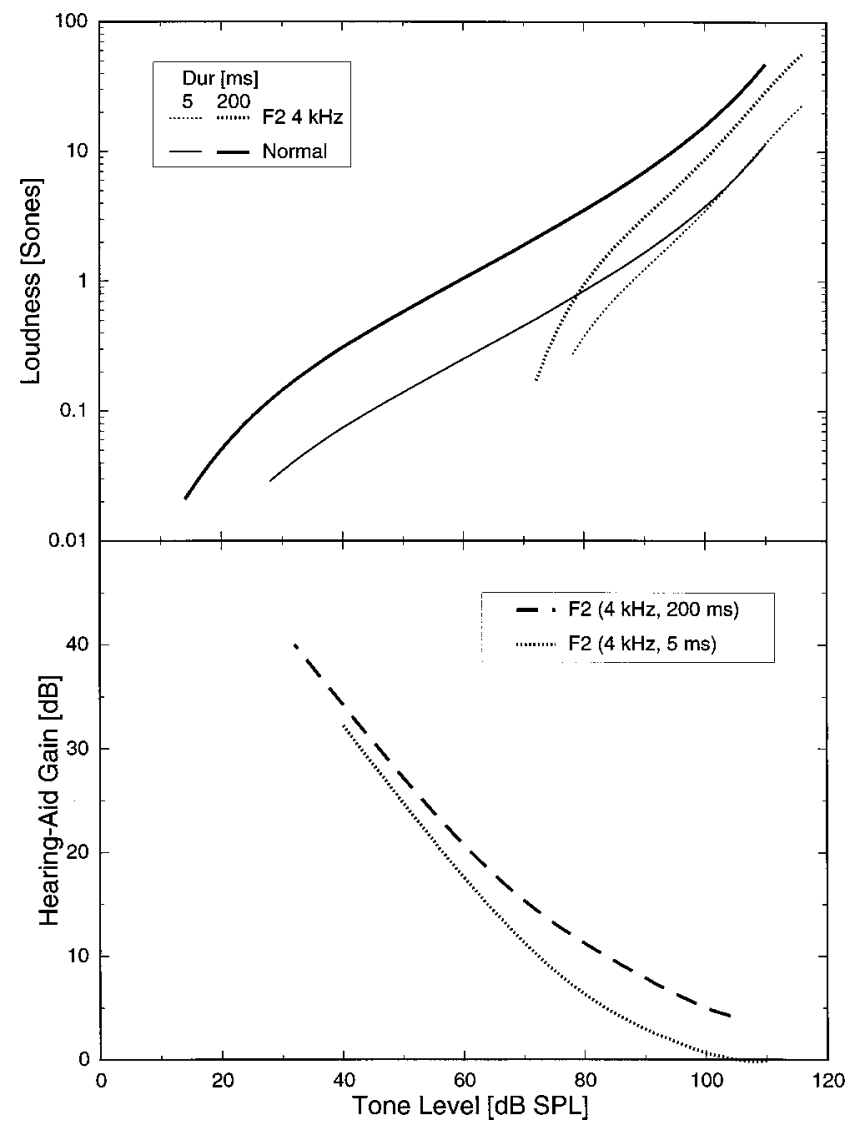

FIG. 10. Loudness functions and predicted hearing-aid gain necessary to restore normal loudness for listener F2, who showed very small amounts of temporal integration. The upper panel shows loudness functions for 5- (thin lines) and 200-ms tones (thick lines) for normal listeners (solid lines) and for listener F2 at $4 \mathrm{kHz}$ (dotted lines). The lower panel shows the hearingaid gain predicted as the horizontal distance between the normal and impaired loudness functions for 5- (dotted line) and 200-ms tones (dashed line). Because F2's abnormally small amounts of temporal integration were assumed to reflect abnormal adaptation of auditory activity, the equalloudness-ratio hypothesis predicts that a higher gain is needed to restore loudness for 200- than for 5-ms tones.

did not alter the loudness ratio between long and short tones. Whereas this assumption seems reasonable for most listeners with cochlear impairments, it has yet to be verified. In addition, it may be incorrect for some listeners such as F2, who shows markedly lower-than-normal amounts of temporal integration. Unusually small amounts of temporal integration may reflect an abnormally rapid adaptation of neural activity in the auditory system, which is likely to reduce the rate at which loudness increases with duration. This would result in a smaller-than-normal loudness ratio between long and short tones. The amount of temporal integration for $\mathrm{F} 2$ at $4 \mathrm{kHz}$ was only about $4 \mathrm{~dB}$ near her threshold of $68 \mathrm{~dB}$ SPL, increased to a maximum of about $9 \mathrm{~dB}$ around $90 \mathrm{~dB}$ SPL, and decreased to about $6 \mathrm{~dB}$ at high SPLs. These small amounts of temporal integration would imply very steep loudness functions, if the loudness ratio between long and short tones were normal. If the loudness ratio between 200- and 5-ms tones is assumed to be reduced to about 2.3 by abnormal adaptation, however, the loudness functions predicted for F2 have the same slope as the normal loudness functions at high SPLs as shown in Fig. 10.
Because the abnormal adaptation ought to reduce the loudness of long-duration stimuli, the vertical position of the predicted loudness functions in the top panel of Fig. 10 was chosen to show normal loudness for 5-ms tones at high levels, but reduced loudness (incomplete recruitment) for long tones. The gain functions predicted for loudness restoration are shown in the lower panel. As for the listener with a normal loudness ratio between long and short tones (and, presumably, normal adaptation), the gain functions require wide-dynamic-range compression. However, due to F2's altered loudness ratio between long and short tones, the gain required for 5-ms tones is no longer the same as that for 200-ms tones. The gain for a 5-ms tone (dotted line) decreases to $0 \mathrm{~dB}$ at high levels as follows from the assumption of complete recruitment; the gain for a 200-ms tone (dashed line) also decreases with increasing level, but is always higher than that for the 5-ms tone. Whereas the gain for any given input SPL and the detailed form of the gain function depend critically on the vertical position chosen for F2's loudness functions, the prediction of higher gain for long than for short stimuli does not. It results from the assumption of a reduced loudness ratio.

The goal of having higher gain for long than for short sounds may be met by properly designed digital signal processing. However, such processing is likely to introduce an undesirable delay and/or distortion to the signal envelope, which could reduce speech intelligibility and outweigh any advantage gained by restoring loudness. Therefore, it may be advantageous to use the same gain for brief and long signals, even in cases of abnormal adaptation and unusually small amounts of temporal integration. Certainly, a durationindependent gain function ought to provide a reasonable approximation to restoration of normal loudness because the gains required for brief and long signals of equal SPL usually differ by only a few $\mathrm{dB}$. However, the optimal gain for listeners with abnormal adaptation may be slightly lower than the gain derived from loudness measurements with long signals.

\section{SUMMARY}

The present study obtained measurements of loudness balance between 5- and 200-ms tones at various frequencies to assess how temporal integration for loudness varies with level in 15 listeners with hearing impairments of predominantly cochlear origin and in a control group of seven agematched listeners with normal hearing. The main conclusions are:

(1) The amount of temporal integration for loudness, defined as the level difference between equally loud 5- and 200-ms tones, varies nonmonotonically with level and shows a maximum at moderate SLs in all normal listeners and in most impaired listeners.

(2) The effect of level on the amount of temporal integration varies considerably among normal listeners and varies even more among impaired listeners.

(3) The amount of temporal integration for loudness near 
threshold generally approaches that for detection and tends to be smaller in impaired listeners than in normal listeners.

(4) The amount of temporal integration for loudness at high SPLs usually is about the same or even slightly larger in impaired listeners than in normal listeners tested at the same SPLs.

(5) When evaluated at equal SLs, the impaired listeners tend to show normal or less-than-normal amounts of temporal integration, except when the hearing loss is abrupt-i.e., increases more than $50 \mathrm{~dB}$ per octave above the test frequency.

(6) The amounts of temporal integration for loudness in listeners with abrupt losses are much larger than normal for frequencies at or somewhat below the highest frequency of near-normal thresholds.

(7) The large amounts of temporal integration obtained for listeners with abrupt losses are consistent with these listeners' flatter-than-normal loudness functions and the hypotheses that the loudness ratio between equal-SPL long and short tones is independent of SPL and is the same in normal and most impaired listeners.

(8) Overall, the results for impaired listeners appear consistent with expectations based on knowledge of the general properties of their loudness-growth functions and the equal-loudness-ratio hypothesis. The large variation of the impaired listeners' temporal-integration functions may reflect large variation in their loudness-growth functions resulting from differing balances between innerand outer-hair-cell dysfunction.

(9) Application of the equal-loudness-ratio hypothesis to the present data indicates that the hearing-aid gain necessary to restore normal loudness is independent of stimulus duration for most impaired listeners. However, some impaired listeners have abnormally small amounts of temporal integration, which may result from abnormally fast adaptation of auditory activity. For these listeners, the gain required for restoring normal loudness may be higher for long than for brief stimuli.

\section{ACKNOWLEDGMENTS}

The authors are grateful for the efficient and helpful collaboration with Nikolai Bisgaard, Ole Dyrlund, and Jesper Rye Nielsen at GN Danavox, who provided the impaired listeners for this study and who provided loudness-scaling data for listener MF3. The reviewers, Walt Jesteadt and Brian C. J. Moore, provided very helpful comments to an earlier version of this paper. We are especially grateful to Brian C. J. Moore for providing results of model calculations for MF3. Part of this research was carried out at the Technical University of Denmark. It was supported by NIH-NIDCD Grant No. RO1 DC02241.

Bacon, S. P., and Gleitman, R. M. (1992). "Modulation detection in subjects with relatively flat hearing losses,' J. Speech Hear. Res. 35, 642653.

Bacon, S. P., and Viemeister, N. F. (1985). "Temporal modulation transfer functions in normal-hearing and hearing-impaired subjects," Audiology 24, 117-134.
Barfod, J. (1978). "Multichannel compression hearing aids: Experiments and considerations on clinical applicability," in Sensorineural Hearing Impairment and Hearing Aids, edited by C. Ludvigsen and J. Barfod, Scand. Audiol. Suppl. 6, 315-339.

Buus, S., and Florentine, M. (1989). "Simulated hearing loss as a baseline for the assessment of auditory function in cochlearly impaired listeners," in Proceedings of the 15th Annual Bioeng. Conference, edited by S. Buus (IEEE, Piscataway, NJ), pp. 19-20.

Buus, S., Florentine, M., and Poulsen, T. (1997). "Temporal integration of loudness, loudness discrimination, and the form of the loudness function," J. Acoust. Soc. Am. 101, 669-680.

Buus, S., Florentine, M., and Poulsen, T. (1997). "Temporal integration of loudness in listeners with normal hearing and sensorineural hearing loss," in Proceedings of the 2nd Biennial Hearing Aid Research and Development Conference (NIDCD/VA, Bethesda, MD), p. 42.

Buus, S., Florentine, M., and Poulssen, T. (1997). "Loudness of brief tones in listeners with normal hearing and sensorineural hearing loss,' ASHA Leader 2(15), 143.

Buus, S., Müsch, H., and Florentine, M. (1998). "On loudness at threshold,', J. Acoust. Soc. Am. 104, 399-410.

Carlyon, R. P., Buus, S., and Florentine, M. (1990). “Temporal integration of trains of tone pulses by normal and by cochlearly impaired listeners,", J. Acoust. Soc. Am. 87, 260-268.

Delgutte, B. (1990). "Physiological mechanisms of psychophysical masking: Observations from auditory-nerve fibers,', J. Acoust. Soc. Am. 87, 791-809.

Fastl, H. (1975). "Loudness and masking patterns of narrow noise bands,', Acustica 33, 266-271.

Florentine, M., and Buus, S. (1986). "Simulated hearing loss: a tool for comparing normal and impaired hearing," Proceedings of the 12th International Congress of Acoust., Vol. 1, B11-3.

Florentine, M., Buus, S., and Hellman, R. P. (1997). "A model of loudness summation applied to high-frequency hearing loss," in Modeling Sensorineural Hearing Loss, edited by W. Jesteadt (Erlbaum, Mahwah, NJ), pp. 187-198.

Florentine, M., Buus, S., and Poulsen, T. (1996). “'Temporal integration of loudness as a function of level,', J. Acoust. Soc. Am. 99, 1633-1644.

Florentine, M., Buus, S., and Robinson, M. (1998). "'Temporal integration of loudness under partial masking," J. Acoust. Soc. Am. 104, 999-1007.

Florentine, M., Fastl, H., and Buus, S. (1988). "Temporal integration in normal hearing, cochlear impairment, and impairment simulated by masking,"' J. Acoust. Soc. Am. 84, 195-203.

Florentine, M., Reed, C. M., Rabinowitz, W. M., Braida, L. D., Durlach, N. I., and Buus, S. (1993). "Intensity perception. XIV. Intensity discrimination in listeners with sensorineural hearing loss,' J. Acoust. Soc. Am. 94, 2575-2586.

Florentine, M., and Zwicker, E. (1979). "'A model of loudness summation applied to noise-induced hearing loss," Hearing Res. 1, 121-132.

Hall, J. W., and Grose, J. H. (1989). "Spectro-temporal analysis and cochlear hearing impairment: Effects of frequency selectivity, temporal resolution, signal frequency and rate of modulation,' J. Acoust. Soc. Am. 85, 2550-2562.

Hellman, R. P. (1974). "Effect of spread of excitation on the loudness function at $250 \mathrm{~Hz}$,' in Sensation and Measurement, edited by H. R. Moskowitz, B. Scharf, and J. C. Stevens (Reidel, Dordrecht, Holland), pp. 241-249.

Hellman, R. P. (1994). "Relation between the growth of loudness and highfrequency excitation,' J. Acoust. Soc. Am. 96, 2655-2663.

Hellman, R. P., and Meiselman, C. H. (1991). "Loudness relations for individuals and groups in normal and impaired hearing," J. Acoust. Soc. Am. 88, 2596-2606.

Hellman, R. P., and Meiselman, C. H. (1993). "Rate of loudness growth for pure tones in normal and impaired hearing,', J. Acoust. Soc. Am. 93, 966-975.

Jesteadt, W. (1980). "An adaptive procedure for subjective judgments," Percept. Psychophys. 28, 85-88.

Killion, M. C. (1993). "The $K$-amp hearing aid: An attempt to present high fidelity for persons with impaired hearing,' Am. J. Audiol. 2, 52-74.

Levitt, H. (1971). "Transformed up-down methods in psychoacoustics,' J. Acoust. Soc. Am. 49, 467-477.

McDermott, H. J., Lech, M., Kornblum, M. S., and Irvine, D. R. F. (1998). "Loudness perception and frequency discrimination in subjects with steeply sloping hearing loss: Possible correlates of neural plasticity,' J. Acoust. Soc. Am. 104, 2314-2325. 
Miskolczy-Fodor, F. (1960). "Relation between loudness and duration of tonal pulses. III. Response in cases of abnormal loudness function,' J. Acoust. Soc. Am. 32, 486-492.

Moore, B. C. J. (1995). Perceptual Consequences of Cochlear Damage (Oxford University Press, Oxford).

Moore, B. C. J. (1998). Personal communication.

Moore, B. C. J., and Glasberg, B. R. (1986). "The role of frequency selectivity in the perception of loudness, pitch and time,', in Frequency Selectivity in Hearing, edited by B. C. J. Moore (Academic, London), pp. 251-308.

Moore, B. C. J., and Glasberg, B. R. (1997). " A model of loudness perception applied to cochlear hearing loss,', Aud. Neurosci. 3, 289-311.

Moore, B. C. J., Launer, S., Vickers, D. A., and Baer, T. (1998). “Loudness of modulated sounds as a function of modulation rate, modulation depth, modulation waveform, and overall level,' in Psychophysical and Physiological Advances in Hearing, edited by A. R. Palmer, A. Rees, A. Q. Summerfield, and R. Meddis (Whurr, London), pp. 465-472.

Moore, B. C. J., and Oxenham, A. J. (1998). "Psychoacoustic consequences of compression in the peripheral auditory system,' Psychol. Rev. 105, $108-124$.

Moore, B. C. J., Peters, R. W., and Glasberg, B. R. (1996). "Detection of decrements and increments in sinusoids at high overall levels, ' J. Acoust. Soc. Am. 99, 3669-3677.

Moore, B. C. J., Shailer, M. J., and Schooneveldt, G. P. (1992). "Temporal modulation transfer functions for band-limited noise in subjects with cochlear hearing loss,' Br. J. Audiol. 26, 229-237.

Oxenham, A. J., and Moore, B. C. J. (1997). "Modeling the effects of peripheral nonlinearity in normal and impaired hearing," in Modeling Sensorineural Hearing Loss, edited by W. Jesteadt (Erlbaum, Mahwah, NJ), pp. 273-288.

Oxenham, A. J., Moore, B. C. J., and Vickers, D. A. (1997). "'Short-term temporal integration: Evidence for the influence of peripheral compression,' J. Acoust. Soc. Am. 101, 3676-3687.

Patuzzi, R. B. (1993). "Otoacoustic emissions and the categorization of cochlear and retrocochlear hearing losses,'” Br. J. Audiol. 27, 91-95.

Pedersen, C. B., and Poulsen, T. (1973). "Loudness of brief tones in hearing-impaired ears,' Acta Oto-Laryngol. 76, 402-409.

Port, E. (1963). "Über die Lautstärke einzelner kurzer Schallimpulse,', Acustica 13, 212-223.

Poulsen, T. (1981). "Loudness of tone pulses in a free field,' J. Acoust. Soc. Am. 69, 1786-1790.

Richards, A. M. (1973). "Loudness growth under masking: relation to true sensorineural impairment,', J. Speech Hear. Res. 16, 597-607.
Richards, A. M. (1977). "Loudness perception for short-duration tones in masking noise," J. Speech Hear. Res. 20, 684-693.

Robles, L., Ruggero, M. A., and Rich, N. C. (1986). "Basilar membrane mechanics at the base of the chinchilla cochlea I. Input-output functions, tuning curves, and phase responses," J. Acoust. Soc. Am. 80, 1364-1374.

Ruggero, M. A., and Rich, N. C. (1991). "Furosemide alters organ of Corti mechanics: Evidence for feedback of outer hair cells upon the basilar membrane,"' J. Neurosci. 11, 1057-1067.

Scharf, B. (1961). "Loudness summation under partial masking,'” J. Acoust. Soc. Am. 64, 1036-1040.

Scharf, B. (1970). "Critical bands," in Foundations of Modern Auditory Theory, Vol. I, edited by J. V. Tobias (Academic, New York), pp. 157202.

Scharf, B. (1978). “'Loudness,'” in Handbook of Perception: Vol. 4. Hearing, edited by E. C. Carterette and M. P. Friedman (Academic, New York), pp. 187-242.

Steinberg, J. C., and Gardner, M. B. (1937). "The dependence of hearing impairment on sound intensity," J. Acoust. Soc. Am. 9, 11-23.

Stephens, S. D. G. (1973). "Auditory temporal integration as a function of intensity,' J. Sound Vib. 37, 235-246.

Stevens, S. S. (1955). "The measurement of loudness," J. Acoust. Soc. Am. 27, 815-827.

Yates, G. K. (1990a). "The basilar membrane input-output function," in The Mechanics and Biophysics of Hearing, edited by P. Dallos, C. D. Geisler, J. M. Matthews, M. A. Ruggero, and C. R. Steele (Springer, New York), pp. 106-113.

Yates, G. K. (1990b). "Basilar-membrane nonlinearity and its influence on auditory-nerve rate-intensity functions," Hearing Res. 50, 145-162.

Zhang, C., and Zeng, F. (1997). "Loudness of dynamic stimuli in acoustic and electric hearing," J. Acoust. Soc. Am. 102, 2925-2934.

Zwicker, E. (1961). "Subdivision of the audible frequency range into critical bands (Frequenzgruppen)," J. Acoust. Soc. Am. 33, 248.

Zwicker, E. (1977). " Procedure for calculating loudness of temporally variable sounds," J. Acoust. Soc. Am. 62, 675-682.

Zwicker, E. (1984). "Dependence of post-masking on masker duration and its relation to temporal effects in loudness," J. Acoust. Soc. Am. 75, 219-223.

Zwicker, E., and Fastl, H. (1990). Psychoacoustics-Facts and Models (Springer, Berlin).

Zwislocki, J. J. (1965). "Analysis of some auditory characteristics," in Handbook of Mathematical Psychology, edited by R. D. Luce, R. R. Bush, and E. Galanter (Wiley, New York), pp. 1-97. 